\title{
Yabancı Dil Eğitiminde Yazma Eğitimi Yaklaşımlarının Gözden Geçirilmesi ve Yazma Becerisinin Diğer Becerilerle İlişkilendirilmesi
}

\author{
DOI: 10.26466/opus.744508
}

$*$

\author{
Erdem Akbaş * \\ *Dr. Öğretim Üyesi, Erciyes Üniversitesi, Eğitim Fakültesi, Kayseri/Türkiye \\ E-Posta: erdemakbas@erciyes.edu.tr \\ ORCID: $\underline{0000-0003-2204-3119}$
}

Öz

Dil öğrenim süreci bir bütün olarak algılandiğında, etkili iletişim için, dil öğrenenlerin geliştirmesi beklenen ana becerilerden birisi de yazma becerisidir. Ancak, yabancı dil eğitiminde çoğu zaman göz ardı edilen yazma becerisi, hem öğretmenler hem de öğrenciler tarafından en zahmetli beceri olarak düşünülmektedir. Bu çalışmanın amacı, yazma eğitiminde kullanılabilecek en temel yaklaşımları irdelemek ve bu becerinin diğer dil becerileriyle bütünleştirilmesini çeşitli örneklerle tartışmaktır. Bu şekilde bütün becerilerin bütünleştirildiği bir dil eğitimi, Burgess (1994)'ın da vurguladığı gibi, öğrencilerin bir başka dili öğrenirken hem alımlayıcı (receptive) hem de üretken (productive) becerilerini daha aktif kullanabilmesini sağlayacaktır. Genellikle öğrencilere hangi konuda yazacakları tanıtıldığında onların konu ile ilgili az bilgiye sahip olmaları bir şikâyet konusu olarak karşımıza çıkabilmektedir. Bu problemin üstesinden gelebilmek için Jiang ve Du (2006)'nun önerdiği gibi, öğretmenlerin yazma aktivitesini yoğunlaştırılmış okuma sınıfları ile birleştirmesi pratik bir çözüm olabilir. Diğer becerilerden yalıtılmış bir yöntemin aksine yazma eğitiminin diğer dil becerileri ile ilişkilendirilerek öğretilmesi, öğrencilerin sınıf içerisinde daha doğal bir iletişim kurmasını sağlayabilir. Dili işleme stratejilerinin yanında dil becerilerin bütünleşik bir şekilde sunulduğu sinıf aktiviteleri dil öğretiminin söylem açısından başarılı olmastnın yolunu açabilir. Buradan hareketle, öğretim bağlamı, dersin hedefleri, öğrencilerinin istekleri ve seviyeleri gibi farklı bileşenleri değerlendirerek en doğru yazma yaklaşımına karar verilebilir. Çalışmada çeşitli yazma eğitimi yaklaşımları farklı öğretim bă̆lamlarına atıfta bulunarak değerlendirildikten sonra yazma becerisinin diğer becerilerle bütünleştirilmesi için bazı tartışmalar ve konu bazl örneklemeler yapılmıştır.

Anahtar Kelimeler: yazma eğitimi yaklaşımları, bütünleşik dil öğretimi, ürün süreç ve tür odaklı yazma eğitimi, yazma becerisi 


\title{
Revisiting Approaches to Teaching Writing and Integration of the Writing Skill with others in Foreign Language Education
}

\begin{abstract}
Considering the language learning process as a whole, for an effective communication, foreign language learners are supposed to master writing skill in the target language as well. Nevertheless, writing skill has been one of the most neglected skills in language education since it is likely to be accepted as hard by both language teachers and learners. The aim of the article is to zoom in on the major approaches to teaching writing in foreign language education, English in particular, and discuss the integration of the skill with teaching other language skills with examples. As is highlighted by Burgess (1994), such an integrated way of skills in language education is of great importance in terms of triggering learners to make use of both receptive and productive skills on the way of learning another language. Students seem to complain about the writing topic in which they have little or no knowledge but are asked to write on. In order to minimize it, a practical solution suggested by Jiang and Du (2006) can be followed to integrate writing classes with highly concentrated reading classes to support them. Unlike teaching writing in isolation, teaching writing skill integrated to other major skills appears to bring a case of spontaneous and natural communication into the language classroom. Activities with integrated skills could also pave the way for providing learners with the required discourse knowledge to be successful in using language. It is highly possible to decide on the most feasible writing approach by taking a range of issues (i.e., teaching context, objectives, interests and levels of leaners) into account. After reviewing the approaches to teaching writing by referring back to various teaching contexts, the article touches upon ways of integrating teaching writing skills with different types of activities.
\end{abstract}

Keywords: approaches to teaching writing, integrated-skills teaching, product process and genre approaches, writing skills 


\section{Giriş}

İngilizce'nin günümüzde yakalamış olduğu statünün yansımaları arasında birçok yabancı dil öğretim bağlamında (örn. İngilizce'nin ikinci dil olarak öğretimi-TESL, İngilizce'nin yabancı dil olarak öğretimi-TEFL, Yabancılara İngilizce öğretimi-TESOL) İngilizce öğretimi oldukça önemli bir role sahip olmuştur. Bununla ilişkili olarak, öğretmenler öğrencilerinin ihtiyaçlarını ve isteklerini karşılamak adına dil öğretiminde farklı yaklaşımlar ve metotlar kullanmaya başlamıştır. Anadilin edinilmesi süreci ile kıyaslandığında yabancı dil öğrenimi ve öğretimi açısından öğrenicilerin hedef dilde sahip olması gereken dört beceriyi (dinleme, konuşma, okuma ve yazma) geliştirmelerine odaklanılması gerekliliği ortaya çıkmıştır. Özellikle, İngilizce'nin ortak dil (Lingua Franca) olması nedeniyle de İngilizce dilinin kullanıcılarının, farklı dillerin kullanıcılarına hitap etmeleri ve onlarla anlaşabilmeleri için yazma becerilerini daha etkili olarak kullanarak yazınsal bir iletişim kurmaları daha da önemli bir hale gelmiştir. Ancak, yabancı dil eğitiminde yazma becerisi hem öğretmenler hem de öğrenciler tarafından en zahmetli beceri olarak görülmüştür (Hocaoğlu ve Ocak, 2019, s.65; Thaqi Jashari ve Dagarin Fojkar, s.81; Walker ve Sampson, 2013, s.1273)

İngilizce'yi yabancı dil öğrenenlerin, bireysel olarak yazılı ve sözlü söylemler oluştururken kullandıkları dilsel öğelerin benzer olduğu düşünülse de, yazılı söylemler aracilığıyla uzak noktaya temas (contact at a distance, Byrne, 1979) etmeye çalışmaktadırlar. Aynı zamanda, bazı yapıların ve aspektlerin bu farklı söylemlere uygulanması da farklılık göstermektedir. Örneğin, yazılı metinlerde, dil kullanıcılarının kayda değer ölçüde dilsel öğelere bağlı kalması, söylem topluluğu tarafından beklenen yapıda ve tavırda dili kullanması ve metni organize etmeye odaklanması gerekmektedir ve hatta öğretim bağlamında dil öğretmenlerinin birçok noktada yönlendirme yapması yoluyla bu öğrenicilerin bu beceriyi kazanmasının yolu açlabilmektedir. Ancak yabancı dil yazma eğitiminde en başta görülen problemlerden birisi, öğretmenlerin kendi bağlamlarına özgü hangi yaklaşım yoluyla bu beceriyi kazandırabileceği üzerinedir. Ayrıca dil öğretmenlerinin diğer becerilerin hangi yollarla yazma becerisini destekleyecek şekilde planlanması gerektiği noktasında da sıkıntı yaşayabileceği ileri sürülebilir.

Bu çalışmanın amacı, yazma eğitiminde kullanılabilecek en temel yaklaşımların irdelenmesi ve bu becerinin diğer dil becerilerine ne şekilde entegre 
edilebileceğini örneklendirmektir. Sınıf içi ve sınıf dışı aktivitelerle ve diğer dil becerileri ile de desteklenebilecek bir yazma eğitimi ortamında, ögrencilerin genellikle ihmal edilen bu beceriyi daha iletişimsel bir seviyede kullanabilmelerine firsat sağlanabilir. Bu şekilde diğer becerilerle kaynaştırılacak bir yazma eğitimi, Burgess (1994)'ın da vurguladığı gibi, öğrencilerin hem alımlayıcı (receptive) hem de üretken (productive) becerilerini daha aktif kullanabilmesini sağlayacaktır.

Bu makalenin üç ana bölümü bulunmaktadır. İlk bölüm, yazma eğitiminde kullanılan en önemli üç yaklaşım olan Ürün Odaklı (Product), Süreç Odaklı (Process) ve Tür Odaklı (Genre) yazma yaklaşımlarının irdelenmesi ve sentezlenmesi üzerine tartışmalar sunarken ikinci bölümde makalenin odak noktası, bazı eğitsel materyallerin sunulması yoluyla yazma eğitiminin diğer becerilerle kaynaştırılması olacaktır. Sonraki bölümde, ilk bölümde sunulan yaklaşımların dışında farklı bir yaklaşımı öne çıkararak yazma eğitiminin ve dil öğretiminin en önemli noktalarını tartışacaktır.

\section{Yazma Eğitimi Yaklaşımlanı}

Dil öğrenim süreci bir bütün olarak algılandığında, etkili iletişim için, dil öğrenenlerin geliştirmesi beklenen ana becerilerden birisi de yazma becerisi olarak değerlendirilmektedir. Nitekim yazma ile zihindeki duygular, düşünceler ve bilgiler okuyucuya iletilebilmektedir. Tabak ve Göçer'in (2013, s. 148) de bahsettiği gibi, yazma becerileri eğitimde önemli bir yer almaktadır. En iyi yazma eğitimi için çeşitli yaklaşımlar ön plana çıkmaktadır. Hem anadil hem de yabancı dil eğitiminde kullanılabilecek yazma eğitimi yaklaşımlarından olan Ürün Odaklı, Süreç Odaklı ve Tür Odaklı yazma eğitimi yaklaşımları özellikle İngilizce'nin yabancı dil olarak öğretilmesinde yardımcı olabilecek materyal ve bağlamlar ışığında alt bölümlerde tartışılmaktadır.

\section{Ürün Odaklı Yazma Eğitim Yaklaşımı}

Bu yazma eğitimi yaklaşımının temelinde, dil kullanıcılarının sahip oldukları bilgileri herhangi bir sürece odaklanmadan aktardığı ve öğretmenin de sürece müdahalede bulunmadığı fakat daha çok son aşamada değerlendirme ile sonuçlanan bir metin oluşturma modeli yatmaktadır. Ürün odaklı yakla- 
şım, yazma becerisini temel olarak dilsel bilgiye ve aktarımına dayandırmaktadır. Badger ve White (2000)'ın deyişle, doğru kelime kullanımından dil kurallarına ve bilginin aktarımına kadar sonuç odaklı bir yapıya sahiptir. Asıl amaç, öğrencilerin sunulan metinlerdeki kalıplaşmış dilsel yapıları kullanmasını sağlamaktır. Daha sonra öğrencilerin yapması gereken bu dilde yerleşmiş kalıpları, kelimeleri ve bağdaşıklık araçlarını kullanmaktır. Fakat önemli olan noktalarda biri, metnin üretimine geçilmeden önce, hedef kalıplara sahip bir metnin tanıtılması ve incelenmesi etkili kullanımların altının çizilmesi için gereklidir. Badger ve White (2000) bu yaklaşımın dört önemli adımda tamamlanacağını önermektedir. Bu aşamalar arasında, Tanıma, Kontrollü Yazma; Güdümlü Yazma ve Serbest Yazma bulunmaktadır. Bu adımların takip edilmesiyle öğrencilerin özel dilsel kalıplara ve kelime kullanımına rahatça erişmeleri sağlanarak bu kullanımların rutin haline gelmesi hedeflenmektedir. İlk aşama olan Tanıma ile öğrencilerin bir metnin çeşitli niteliklerinin farkına varması sağlanmaktadır. Örneğin, İngilizce'nin yabancı dil ya da ikinci dil olarak öğretildiği bir sınıfta, öğrencilerin bir üniversite başvuru mektubu yazması isteniyorsa, bu metnin dilsel öğelerine erişilebilmesi için bir model tanıtılmaktadır. Daha sonra öğrenciler cümle yapıları, kelime seçimi ve kullanımı gibi özel dilsel öğelere yönlendirilmektedir. Kontrollü ve Güdümlü yazma aşamalarının uygulamaya konulmasının en önemli sebebi, öğrencilerin verilen model metin üzerinden pratik yapabilmesini sağlamaktır. Son olarak, Serbest yazma aşamasına geçilmesiyle öğrencilerin hedef metni temel alarak benzer bir metin üretilmesi sağlanmaktadır (Badger ve White, 2000, s. 156). Ürün odaklı yazma yaklaşımın takip edilmesi yoluyla öğrencilerin kendi öğrenmelerinden sorumlu olması sağlanabilirken aynı zamanda hedefe alınmış metne özgü belirli dil yapıları ve kelimeleri yetkin bir şekilde kullanmalarına zemin hazırlanabilmektedir.

Bu aşamalara ek olarak, Nunan (1991), ürün odaklı yazma yaklaşımının alt basamaklarında yer alabilecek yansılama (imitation), kopyalama ve dönüştürmenin öbek, cümle ve paragraf seviyesinde gerçekleşmesi için öğrencilerin bu seviyelerde yetkin olması gerektiğini vurgulamıştır. Buradan hareketle, ürün odaklı yazma yaklaşımını benimseyen yazma becerisi sınıflarının tümevarımı esas alarak cümle yapıları ve bağdaşıklık araçları üzerine odaklanması gerekmektedir. Ancak, günümüzün dil eğitimi görüşlerinin söylem seviyesinde ve tümdengelim yoluyla tanımlanması sebebiyle tümevarım mo- 
delinin geleneksel bir yöntem olarak tanımlanmasına sebep olmaktadır. Sonuç olarak, bu yazma yaklaşımı her ne kadar mekanik bir bakış açısıyla hedef ürünü merkeze almasa da öğrencilerin sağlanan metinleri yansılaması yoluyla yapıları, bağlamı ve metin organizasyonunu keşfetmesine olanak sunarak yazma eğitiminde kullanılmaktadır.

\section{Süreç Odaklı Yazma Yaklaşımı}

Gao (2007)'ya göre, süreç odaklı yazma yaklaşımının ortaya çıkması ürün odaklı yazma yaklaşımının çeşitli eleştiriler alması ile yakından ilişkilidir. Yazma becerisinin giderek söylem odaklı yaklaşımlarla ilişkilendirilmesi ve tümevarım bakış açısına sahip öğrenci merkezli bir eğitimin süreç odaklı yazma yaklaşımının ortaya çıkmasını sağladığı söylenebilir. Bu yaklaşımın, öğrenenlerin pratiğe dönük ihtiyaçlarının artışının karşılanabilmesi için önemli bir adım olduğu düşünülmektedir. Zeng (2005), süreç odaklı yazma yaklaşımının yazma becerisini hem birçok farklı safhadan oluşan hem de öğrencilerin bilişsel olarak meşgul eden bir özelliğe sahip olduğunu belirtmiştir. Tribble (1996) süreç odaklı yaklaşımın yazarların yaratıcılıklarına odaklanan bir model olarak tanımlamaktadır. Benzer bir şekilde, Johnston (1996) da bu yaklaşımın, ürün odaklı yaklaşımın aksine örnek metnin yansılanması yoluyla değil, hedef metnin çeşitli bilişsel süreçleri ön plana çkararak oluşturulması ile yazarların yaratıcılıklarını kullanabileceklerinin altın çizmektedir. Ancak bu yaklaşım nihai ürün olan hedef metni tamamen göz ardı etmemektedir çünkü sonuç ürün yazma sınıflarının vazgeçilemez hedeflerinden birisi olarak kabul edilmektedir.

Adından da anlaşılacağı gibi süreç odaklı yazma çeşitli süreçlerden oluşmaktadır. Bu süreçler arasında ön yazma etkinlikleri (pre-writing activities), taslak oluşturma (drafting), gözden geçirme (revising) ve düzenleme (editing) yer almaktadır (Zeng, 2005, s. 67). Bu süreçler sonucunda bir yazarın fikirlere ulaşması, onları organize etmesi ve en verimli hale getirerek metne son şeklini vermesi beklenmektedir. Bahsi geçen süreçler doğrusal değil döngüsel bir yapıya sahip olarak düşünülebilir. Çünkü bu yaklaşım, yazarların doğrudan hedefe ulaşmasını değil bir tür yazma ile ilişkili döngü mantığını benimsemektedir. Bir başka deyişle, süreç odaklı yaklaşım, herhangi bir alt süreçte yazarın, süreçler arası ileri-geri hareket edebilmesine olanak sağlayarak fikir 
toplanmasından bilgi üretimine, organize edilmesinden bunların tekrar tekrar gözden geçirilmesine kadar birçok etkinliği (Harmer, 2007, s.257) mümkün kılmaktadır. Nihai olarak yazarların kayda değer bir çalışma ortaya koymasını kabul eden bu yöntemde öğretmen de geribildirim ve düzeltmeler önermesiyle etkin bir role sahiptir. Raimes (1991)'e göre, metin üretimi aşamasında öğrencilere yeterli zamanın ve geribildirimin verilmesi çok değerlidir.

Yukarda bahsedilen alt süreçler irdelendiğinde, ön yazma etkinliklerinin yeni fikirler elde etmek için yürütülen bazı aktivitelerden oluştuğu görülmektedir. Bu aktiviteler arasında konu hakkında beyin firtınası yapılması, araştırma ve tartışma yapılması bulunmaktadır. Yabancı dil öğretiminde, bu alt süreçlerde öğretmenin de etkin olarak yer alarak öğrencileri çeşitli noktalara yönlendirmesi sınıf içi etkileşimi de artırdığı için avantaj sağlamaktadır. Ayrıca, Blasingame ve Bushman (2005)'ın da önerdiği gibi, öğrencilerin fikirlerini diğer öğrencilerle paylaşabileceği bir ortamın sağlanması da onlara dil öğrenme sürecinde yazma becerilerini geliştirirken farklı alt becerileri de (örneğin, konuşma ve dinleme) geliştirebilme imkânı sağlamaktadır.

Elde edilen fikirlerin yararı ve kalitesinin değerlendirilmesinin ardından taslak oluşturma sürecinde yazarların birden çok taslak oluşturarak hem bilişsel olarak hem de pratik anlamda yazma fikrine alışmaya başlamalarına imkân sunulmaktadır. Birden çok taslak yapılması yoluyla daha tutarlı metinler ortaya çıkarılabilmektedir. Bu da Hyland (2002)'ın yazma becerisi öğretilmez ama öğrenilir fikrini destekleyen bir olgu olarak düşünülebilir. Öğrencilerin birden çok taslak hazırlayarak yazma sürecinin içerisinde bulunmaları onlara önemli yararlar sağlamaktadır. Örneğin, öğrencilerin tedirgin hissetmeden bir çalışma ile taslak hazırlaması onların motivasyonlarını güçlendirebilmektedir. Ayrıca, yazar, metin ve olası okuyucunun etkisini de göz önüne alan öğrenciler hedefe yönelik bir metin oluşturma sürecini verimli geçirebilirler. Tam bu noktada, yazma eğitimi veren öğretmenin olası bir okuyucu gözüyle taslakların gelişmesine çeşitli yollarla geribildirim vererek katkı sağlaması mümkündür. Buna ek olarak, Hedge (2000) öğretmenin sınıf içerisinde grup çalışmaları yoluyla öğrencilerin diğer öğrenciler tarafından yazılan metinleri okuyarak hem fikir alışverişi hem de o metnin gelişmesi için akran geribildiriminde bulunmasıyla bu sürecin zenginleştirebileceğini belirtmektedir. Örnek olarak, öğrencilerin ikili çalışma ile kısa hikâye yazmaları 
için tasarlanan bir yazma etkinliğinde öğrenciler hem kendi hikâyelerini yazar hem de metinlerin planlanmasinda ve tasarlanmasinda olası okuyucu olarak rol alabilir ve geribildirim verebilirler. Daha sonra gruplar arasında yapılacak tartışmalar sayesinde önemli noktalar ele alınabilir ve bu şekilde de hedef dili kullanarak dinleme ve konuşma becerilerinin kullanılmasına firsat verilebilir. Bu sürecinde sonucunda da öğrenciler taslakları üzerinde tekrar çalışabilir ve değişiklik yapabilirler. Hedge (1988) taslak oluşturma sürecini yazarların ne iletmek istediklerine odaklandıkları bir süreç olarak tanımlarken birçok taslak oluşturma sürecinin yazarların iletmek istediklerini en etkili nasıl ileteceklerini belirlemesine yardımcı olduğunu vurgulamıştır. Oluşturulan taslakların en önemli getirisi metnin bağdaşıklık ve tutarlık açısından iyi bir noktaya gelebilmesidir. White ve Arndt (1991)'a göre, eğer öğrenciler hatasız bir metin için dilsel öğelerin ve kalıpların nasıl kullanılması gerektiğinden çok içerik ve tutarlılık üzerine yoğunlaşırsa bunun ürün metne ulaşmadan daha motive edici olabileceğini ortaya atmıştır.

Süreç odaklı yaklaşımın son aşamaları gözden geçirme ve düzenlemeden oluşmaktadır. Bu aşamaların en önemli noktası, öğrencilerin içerikten ziyade daha çok dilbilgisi ve diğer mekanik (kelime seçimi, yazım kuralları gibi) konuların üzerine eğilmesidir. Blasingame ve Bushman (2005), bu şekilde öğrencilerin vurgulamak istediklerini daha açık ve etkili bir şekilde iletebileceklerini belirtmektedir. Ayrıca metinleri son haline getirmeden önce yazım hatalarının bulunması (proofreading) ve düzenleme ile yazının öğretmen tarafından son değerlendirilmesine geçilmeden uygun bir metin haline gelmesi hedeflenebilir çünkü bu alt basamaklar ile açık ve anlaşlır bir yazınsal ürün ortaya koyulması ifadelerin anlaşılabilirliği açışından önemlidir. Bunun yanı sıra, Tabak ve Göçer (2013)'e göre, bu aşamada gerçek metinlerle yapılacak düzeltme etkinlikleri tek başına verilebilecek dilbilgisi ve yazım kuralları gibi eğitimlerden daha başarılı olabilir. Ayrıca, Badger ve White (2003) tarafından belirtildiği gibi, süreç odaklı yazma yaklaşımında öğretmenin öğrencilerin sahip olduğu potansiyel doğrultusunda onlara yardım etmesi ve bu süreçte aktif bir rol alması beklenmektedir. Bu nokta da öğretmenin geribildirim vermesi önem arz etmektedir. Örneğin, İngilizce'yi yabancı dil olarak kullanan öğrencilerin yazma aktivitelerinde öğretmenleri ile iletişimleri sonucunda ortaya çıkan ve Şekil 1'de sunulan çerçeve ile öğrencilerin metinlerine geribildirimde bulunarak hem onların hem de metinlerin gelişimine olanak sağlanabilir. 


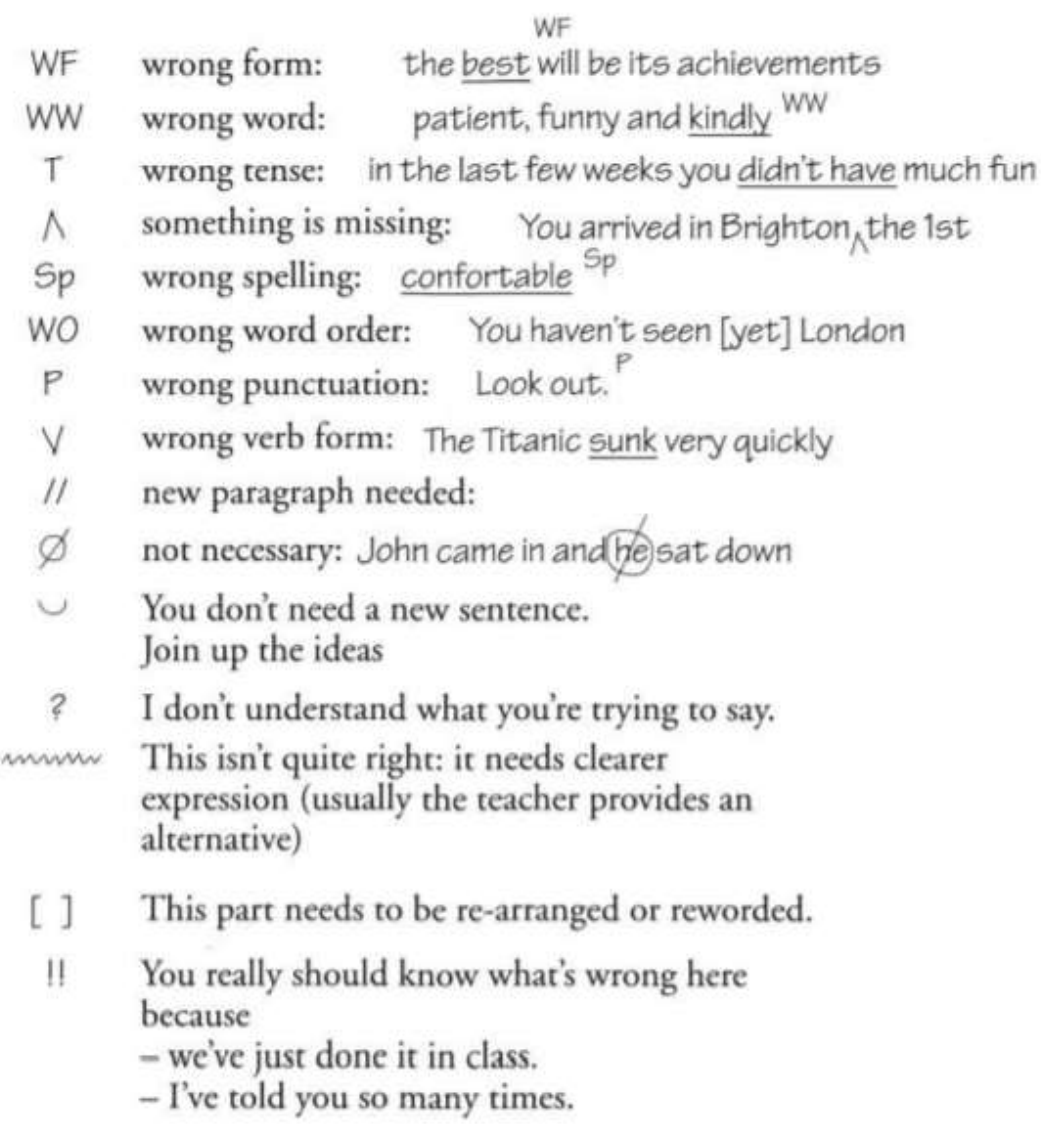

Şekil 1. Yazılı metinlerin düzeltilmesi için kullanılabilecek örnek bir geribildirim sistemi (Hedge, 2000, s. 316).

Bu yaklaşıma yapılan en büyük eleştirilerden birisi, Hyland (2003)'ın bahsettiği gibi, süreç odaklı yazma yaklaşımının yazarları kendi fikirlerini yazabilmeleri için birey olarak görmesi olarak gösterilebilir. Nitekim Gao (2007)'ya göre, bu yaklaşım yazarların metni oluştururken nasıl süreçlerden geçtiğini gösterse de o metne özgü bazı dilsel seçimleri neye dayanarak yaptıklarını açıklayamamaktadır. 


\section{Tür Odaklı Yazma Yaklaşımı}

Tür Odaklı yazma yaklaşımı, metnin başarılı bir şekilde oluşturulması için sistematik rehberlik ilkelerini esas alarak yazma eğitimini destekleyen bir modeldir. Kim (2006), çeşitli sosyal bağlamlarda farklı amaçlar için yazılmış metinlerin önemli özelliklerine yoğunlaşılabileceğini aktarmıştır. Bu açıdan ürün odaklı yazma yaklaşımı ile benzerlik gösterse de sosyal bağlam ve metin amacı gibi daha geniş perspektifler ile tür odaklı yaklaşım farklılık göstermektedir.

Tür odaklı yazma yaklaşımı için Hyland (2002) tarafından önerilen yönergeler "Modelleme, Uzlaşma ve İnşa Etme" (s. 21) olarak adlandırılabilir. Hedef türlerin modellenmesi esnasında, metinlerin hangi sosyal bağlamda kullanıldığı, amaçlarının ne olduğunun yanı sıra retorik ve dilsel öğelerinin de analiz edilmektedir. Bunu takiben, öğrencilerin ve öğretmenlerin tartı̧ma yoluyla doğru bilgi üzerinde uzlaşması aşaması gerçekleştirilir. Öğrencilerin hedef türde kendi metinlerini oluşturması için gerekli yönlendirmenin yapılması bu yaklaşımın son aşaması olarak karşımıza çıkabilir. Öğrencilerin bu sırada yapmaya çalıştıkları hedef türleri modeller üzerinden örnek alarak taslaklar oluşturmasıdır. Bu döngüsel yazma etkinliği farklı İngilizce seviyesine sahip öğrenciler için kullanılabilmektedir. Örneğin, Blasingame ve Bushman (2005) tarafından sunulan şikâyet mektubundan hava raporlarına kadar geniş yelpazedeki türler incelendiğinde, farklı seviyedeki öğrencilerin seviyelerine ve bu türlere maruz kalma sıklıklarına göre çeşitli adaptasyonlar yapılarak tür odaklı yaklaşım yoluyla yazma eğitimi verilebilir. Bir başka deyişle, doğum günü veya tebrik kartı türleri yabancı dil öğrenmeye yeni başlayanlar için tür odaklı bir yaklaşım ile uygulanabilirken deneme, makale veya hikâye türleri daha ileri seviyedeki öğrencilerin yazma eğitimine dâhil edilebilir. Fakat unutmamak gerekir ki, herhangi bir türün daha basit veya karmaşık hali de model olarak sunularak her seviye grubuna tanitılabilir. Bu yöntem ile öğrenciler her türe özgü bağlam, topluluk, amaç ve yazar/okuyucu rolleri (Johns, 1995) hakkında düşünebilecek ve bu konularda daha derin bilgilere ulaşabilecektir.

Tür odaklı yazma yaklaşımı yoluyla yazma eğitimine örnek vermek için Myskow ve Gordon (2010)'un örnekleri incelenebilir. Araştırmacılar, Japonya'da, bir tür olarak üniversite başvuru mektupları lisede tür odaklı yazma yaklaşımı ile öğretime uygun olduğunu ileri sürmektedir. Bu eğitim 
kapsamında öğrencilerin model üniversite başvuru mektupları toplaması ve hem yapısal hem bağlamsal olarak analiz etmesi önem arz etmektedir. Bu aşamada, yazma eğitimini alan öğrencilere sorulacak sorular arasında "Başvuru mektubunuzu kim okuyacaktır?" veya "Bu olası okuyucuların değerleri nelerdir?" (Myskow ve Gordon, 2010, s.287) gibi sorular kanalıyla sosyal bağlamın ve amacın ortaya çıkarılması önerilmiştir. Daha sonra bu sosyal bağlamın kullanılan dili, içeriği ve yapıları nasıl etkilediğinin detaylı bir şekilde analiz edilmesi ile öğrenciler türe özgü kendi metinlerini üretmeye hazırlanmıştır. Bu aktivitedeki sistematik korunarak yer alan üniversite başvuru mektubu türü, farklı bir tür ile (bkz. iş mektubu, şikâyet mektubu veya dilekçe) değiştirilerek öğretim bağlamına ve öğrencilerin seviyelerine uygun bir şekilde kullanılabilir.

Sonuç olarak, eğer öğretmen model alma ve pratik yoluyla öğrencilerinin hedef ulaşmasını hedefliyorsa, tür odaklı yazma yaklaşımı birçok öğrencinin seviyesine uygun olarak yazma eğitimine cevap verebilir (Harmer, 2007, s.261). Ancak, bu noktada, öğretmenin kültür bilgisini de göz önünde bulundurması gerekmektedir çünkü kültür bilgisi sosyal bağlamın anlaşılmasında çok önemli bir yere sahiptir. Bu sebeple, öğretmenin bu yaklaşımı yazma eğitimine dâhil etmesi için aynı zamanda öğrencilerinin neleri bilip neleri bilmediği arasında da bir denge kurmalıdır.

\section{Yazma Becerisinin Diğer Becerilerle İlişkilendirilmesi}

Sanchez (2000)'e göre, İngilizce öğretiminde dört temel beceri olsa da birçok bağlamda bu becerilerin öğretimi diğerlerinden yalıtılmış bir şekilde uygulanmaktadır. Bu durum ise dil sınıflarında etkileşimsel gerçek dil kullanımını teşvik etmek yerine her becerinin sadece kendi içinde değerlendirilmesine neden olmaktadır. Bu temel beceriler gerçek yaşam iletişiminde tamamen birbiri ile bütünleşmiş durumdadır. Örneğin, üniversitede bir ders sırasında, öğrencilerin hem ders vereni ve diğer katılımcları dinlemesi (dinleme becerisi) hem de bu bağlama özgü notlar alması (yazma becerisi) gerekmektedir. $\mathrm{Bu}$ kapsamda, çalışmanın bu bölümünde yazma becerisinin diğer beceriler ile bütünleştirilmesi iki ana başlıkta sunulacaktır. Birincisi alıcı becerilerden birisi olan okuma becerisinin yazma becerisinin temelini oluşturması üzerine bir model iken diğeri yazma becerisinin diğer tüm becerilerle birleştirilmesi kapsamında olacaktır. İkinci modelin biraz daha karmaşık bir yapıya sahip 
olması beklenmektedir çünkü bu bağlamdaki aktivitelerin tematik olarak birbirinin devamı olması beklenmektedir, aksi takdirde amaca ulaşılamayabilir. Ayrıca bu bölümde, farklı ögretim materyalleri ve bağlamları, bir önceki bölümdeki yazma yaklaşımları ile de ilişkilendirilerek yazma becerisinin diğer becerilerle ilişkilendirilmesi sağlanacaktır.

\section{Yazma ve Okuma Becerilerinin Bütünleştirilmesi}

Yazma sınıflarının en büyük sorunlarından bir tanesi, öğrencilerin hangi konu ile ilgili yazacaklarına karar vermek olarak düşünülebilir. Buna ek olarak, öğrencileri konu hakkında motive etmek de bir sorun teşkil edebilmektedir. Motivasyonun bu becerinin etkili bir şekilde kullanılmasındaki rolü, öğrencilerin yeterli özgüvene sahip olarak düşündüklerini ifade edebilmeleri ile yakından ilişkilidir. Genellikle öğrencilere hangi konuda yazacakları tanıtıldığında onların konu ile ilgili az bilgiye sahip olmaları bir şikâyet konusu olarak karşımıza çıkabilmektedir. Bu problemin üstesinden gelebilmek için Jiang ve Du (2006)'nun önerdiği gibi, öğretmenlerin yazma aktivitesini yoğunlaştırılmış okuma sınıfları ile birleştirmesi pratik bir çözüm olabilir.

Shanahan ve Lomax (1986) okuma ve yazma arasındaki ilişkinin doğrusal değil etkileşimsel olduğunu aktarmışlardır. Bu yüzden, yazma öncesinde gerçekleştirilecek okuma etkinlikleri bu iki becerinin bütünleştirilmesi için en etkili yollardan birisi olabilir. Bunun sebebi, öğrencilerin farklı okuma yöntemlerini (hızlı okuma, not alma) kullanarak konu odaklı gerçekçi bilgilere ulaşması ve bunlara aşina olması kendi metinlerinde tartışabilecekleri konular hakkında fikir verecektir.

Bu tarz bir bütünleşme örneği olarak, Farthing ve Pulverness (1994)'in kitabındaki aktivite sunulabilir (Ek A). Bu kitabın Reflection 3 (s. 56-57) kısmı, öğrencilerin Dil ve Kültür hakkında bir okuma parçasına yönlendirildiği ve sonrasında bu parçanın bir özetinin çıkarılmasından önce, öğrencilerin çeşitli yazma öncesi etkinlikleri yapması ve diğer öğrencilerle tartışması etkili bir okuma-yazma becerilerinin ilişkilendirilmesi yolu olarak gösterilebilir. Bu ön yazma etkinliklerini takiben, öğrencilerden metindeki önemli noktaları merkeze alan kısa bir özet yazmaları istenebilir. Bu tarz etkinlikler birçok bağlamda kullanılabilecek olmasına rağmen öğrencilerin hedef dilde metin okuması, not alma, tartışma becerileri de düşünüldüğünde metnin özetinin bu 
etkinlikler dizisiyle çıarılması yükseköğretim bağlamında daha verimli olabilir.

Elsworth ve Rose (1996) tarafından yazılan 'Build Your Skills' ders kitabındaki (Ek B) örnek etkinlik ise ilköğretim seviyesinde daha uygun bir yazma etkinliği sunmaktadır. Ek B'de gösterilen ve ürün odaklı bir yazma yaklaşımı ile tasarlanmış bu etkinlikte okuma parçasının hemen arkasından bir yazma etkinliği öğrencilere verilmiştir. Fakat buradaki en önemli nokta, okunan metnin öğrenciler tarafından yazılacak metin için bir model olmasıdır. Bu şekilde hem okuma hem de yazma becerileri tetiklenirken aynı zamanda öğrencilerin motive olabilmesi için örnek alabilecekleri bir ürün onlara tanıtılmaktadır.

Tür odaklı bir yaklaşım ile yazma aktivitesinin okuma becerisi ile bütünleştirilmesi için, daha önce tartışıldığı gibi, öğrencilerin metnin yazıldığı sosyal bağlamı analiz etmesi ve tartışması gerekmektedir, bu da aynı zamanda okuma becerilerinden yararlanılması anlamına gelmektedir. Eğer öğrencilerin model türleri analiz ve herhangi bir bölümünü üretmek için okuması sağlanırsa, bu başlıca bir yazma ve okuma becerilerinin bütünleştirilmesi anlamina gelmektedir. Öğrencilerin motive olması önemli bir unsur ise, öğretmenler öğrencilerden kendi ilgileri ile doğru orantılı metinler toplamaların ve sınıfa getirmelerini isteyebilir fakat bu aşamada herhangi bir yazma aktivitesinin yapılmaması yerinde olacaktır. Sınıfta yapılması gerekenlerin başında ise metinlerin okunması ve tamamen algılanması gerekecektir. Daha sonra okudukları metinler üzerinden özet veya benzer bir metin üretmeleri istendiğinde kendi ilgileri doğrultusunda seçtikleri metinlerle motive olan öğrenciler büyük ölçüde ders süresine ve verimine katkı sağlayacaktır. Tür odaklı yazma yaklaşımında kullanılmak için tasarlanabilecek bir öğretim materyali, Ek C'de bulunan Swan ve Walter (1985)'a ait orta seviye İngilizce kitabında yer alan etkinlikteki iş başvurusu metninden yola çıkarak oluşturulabilir. Ancak yazma aktivitesine başlanmadan önce öğrencilerin en az iki adet örnek metni içinde bulunduğu sosyal bağlamı da düşünerek okuması, incelemesi ve tartısması beklenebilir. Okuma ve yazma becerilerinin bütünleştirilebileceği bu örneği diğer dil ve sosyal becerileri de düşünerek genişletmek de mümkündür. Örneğin, öğrencilerin yazılan iş başvuru mektuplarından sonra gruplar halinde iş görüşmesi yapması ve en iyi başvuru sahibine, yine önceden sağlanabilecek metinler göz önüne alınarak, bir kabul mektubu yazması tasarlanabilir. 
Sonuç olarak, birçok farklı öğretim bağlamında, öğrenciler yazma becerilerini kullanarak bir metin üretmek durumundaysa, bu etkinlikler verimi artırmak ve dili bir bütün olarak düşünmek için okuma metinleri ve becerileri ile desteklenebilir. Okuma ve yazma becerileri arasındaki dinamizm sayesinde iyi organize edilmiş ve gelişmiş metinler ortaya çıkarılabilir. Bu beceri ilişkilendirmesinin bir başka avantajı ise yazma etkinlikleri için kısıtlı olan sınıf öğretim zamanının daha etkili kullanılmasıdır.

\section{Yazma Becerisinin Diğer Becerilerle İlişkilendirilmesi}

Diğer becerilerden yalıtılmış bir yöntemin aksine yazma eğitiminin diğer dil becerileri ile ilişkilendirilerek öğretilmesi, öğrencilerin sınıf içerisinde daha doğal bir iletişim kurmasını sağlayabilir. Bunun sebebi, öğrencilerin sınıfa doğal bir hava getirebilecek olan diğer becerilerle yazma becerisini birleştirebilmesidir. Gerçek yaşam dilinin karmaşıklığının görülebilmesi ve öğrenilebilmesi için öğrencilerin dilin tüm elementlerine maruz kalıp onları kullanabiliyor olması gereklidir. Celce-Murcia ve Olshtain (2000)'e göre, dili işleme stratejilerinin yanında dil becerilerin bütünleşik bir şekilde sunulduğu sınıf aktiviteleri dil öğretiminin söylem açısından başarılı olmasının yolunu açmaktadır. Çünkü bu şekilde tasarlanmış bir sınıfta kullanılan ve pratiği yapılan dil, gerçek iletişimi yansıtacaktır, bu da Oxford (2000)'un vurguladığı gibi, dil eğitiminde Bütünleşik beceri öğretimi olarak bilinen göreceli olarak yeni bir yaklaşımdır.

Süreç odaklı yazma yaklaşımının uygulandığı sınıflarda, öğrencilerin yazma aktivitelerini yürütecekleri konu hakkında diğer dil becerilerinden yararlanacakları yazma öncesi etkinlikleri kullanması bütünleşik beceri öğretimi açısından önemlidir. Örneğin, beyin fırtınası ve tartışma teknikleri ile ön yazma etkinliklerinin yapıldığı sınıflarda konuşma ve dinleme becerileri de aktif olarak kullanılacaktır. Bu safhada, öğrencilerin konuyu hangi açıdan ele alacakları, nasıl organize edeceklerinin yanında fikirlerini paylaşması sağlanmalıdır. Bu yaklaşımın avantajlarından biri, yazma süreci boyunca öğrencilerin tek başına çalışması yerine akranların birbirlerine destek olmasıdır. Bir öğrencinin bir cümle ile ortaya atacağı bir fikrin, diğerleri tarafından algılanması ve bunun sonucunda fikir alışverişi üzerinden dinleme ve konuşma becerilerinin kullanılması öğrenciler arasında grup çalışması fikrini de canlandıracaktır. Fakat bu şekilde tasarlanacak bir etkinliğin, ortanın üstü veya ileri 
seviyede dil yeterliliğine sahip öğrencilerin bulunduğu sınıflarda kullanılması daha verimli olabilir çünkü bu seviyede öğrencilerin hedef dilde tartışmaya katılmak ve o dilde fikirlerini paylaşmak için daha motive olabileceği ileri sürülebilir. Ancak, süreci kolaylaştırma rolü ile bu sınıfta yer alan bir öğretmen, yapılan tartışmaları dil yeterliliği düşük olan öğrencilere basitleştirerek yöneltebilir. Yapılan bu tarz ön yazma aktivitelerinden sonra, öğrenciler taslak aşamasında da farklı becerilerini kullanarak hedef dili bir bütün şekilde iletişim amaçlı kullanabilir. Akranları ve öğretmenleri ile hedef dilde iletişim kuran öğrenciler hem akranlarından hem de öğretmenlerinden yeni fikirler ve geribildirim alarak metinlerinin oluşma sürecine katkı sağlayabilir. Örneğin, Level 3 Reflections (Farthing ve Pulverness, 1994) kitabındaki Final Project isimli proje (bkz. Ek D), öğrencilere bu proje boyunca dil becerilerinin nasıl çalıştığını fark etmeleri için güven aşılamaktadır. Bu projedeki etkinliklerden birisi öğrencilere kendi araştırma projeleri hakkında öğretmenleri ile bazı tartı̧malar yapması ile ilgilidir. Hedef dilde öğretmenleri ile tartışma yapan öğrenciler, projelerini yazmaya başlamadan önce beyin firtınası ve dolaylı yönden konuşma ve dinleme becerilerine de başvuracaklardır.

Ek E (Cunningham ve Moor, 2005, s. 46), dinleme becerileri ile ilişkilendirilmiş, ürün odaklı yazma yaklaşımına örnek olarak gösterilebilir. Bu aktivitede, öğrencilere bir şikâyet mektubu modeli tanitılmadan önce model metindeki yazarı mutlu etmeyen noktaları çözebilmeleri için özel bir teklif hakkındaki bir reklamı dinlemeleri beklenmektedir. Öğrencilerin bu dinleme etkinliği sırasında hedef metinde (şikâyet mektubu) kullanabilecekleri yapılara ve kelimelere aşinalık kazanması amaçlanmaktadır. Dolaylı olarak ise öğrenciler bu dinleme etkinliği sırasında olan gözden geçirme, amaçları belirleme ve telaffuz gibi dinleme becerilerinin alt becerilerini kullanabilmektedirler. Bir diğer etkinlik tasarımında, öğrencilerin model metni analize başlamadan önce elde ettikleri noktaları akranları ile tartışması yoluyla dilbilgisi, kelime seçimi, yeniden ifade etme gibi konuşma becerilerinin alt becerileri de tetiklenebilir.

Tür odaklı yazma yaklaşımı ile tasarlanan bir yazma eğitiminde, okuma becerisinin yanı sıra, öğretmenler konuşma ve dinleme aktivitelerinden yararlanmak yazma sürecini kolaylaştırabilecek bir örnek teşkil edebilir. Daha önce bahsedildiği gibi, öğrencilerin ilgi alanları dâhilinde ve sosyal bağlamı, amaçları ve dilsel kullanımları analiz edebilecekleri tür örnekleri toplanması- 
nın ardından biçimlendirici ikili veya grup tartısmaları uygulanabilir. İngilizce'nin özel amaçlar için öğretimi (English for Specific Purposes) bağlamında, öğrencilerin çeşitli türlerden yararlanmasını daha etkili kılmak için bu yazma için dil sınıfının aynı zamanda diğer becerileri de etkinleştirmesi oldukça önemlidir. Sanchez (2000), bu tarzda dil becerilerinin ilişkilendirildiği bir yazma eğitimi sınıfının öğrenci özerkliğini (autonomy) teşvik edeceğini ve öğrencilerin tam bu sırada kendilerini ifade etmek ve hedef dili kullanmak için bir ortam oluşturulması gerekmektedir. Bu da onlar için gerekli olan bir başarı duygusunu ve iç motivasyonu sağlayabilecektir. Byrne (1979), yazma eğitiminin diğer becerilerle ilişkilendirilmesi için önerilerde bulunmuştur. $\mathrm{Bu}$ kapsamdaki yazma eğitimi bağlamında öğrencilerin güdümlü yazma aktivitesine geçebilmeleri için hazırlanabilecek bir sözlü alıştırmanın tümleşik dil kullanımını sağlayabileceğini açıtır. Öğrencilere yazma konusu ile yakından ilişkili bir konuşma etkinliği ile not alma becerilerini kullanılabilecekleri bir sınıf ortamını takiben öğrencilere kendi hedef metinlerini oluşturacakları bağımsız yazma aşaması takip edilebilir. Bu şekilde tasarlanabilecek bir sınıf ortamının başarıya ulaşması için aktivite mekanizmalarının iyi tanıtılması ve öğrenciler tarafından iyi anlaşılmış olması önemli noktalardan birisidir.

Okuma, konuşma ve dinleme becerilerine ek olarak, bir alt dil becerisi olarak kelime öğretimi de yazma becerisi ile ilişkilendirilmesi gereken bir öneme sahiptir. Öğretmen tarafından seçilen hedef metin ve konu odaklı kelimelerin yazma süreci başlamadan sınıf içerisinde öğretilmesi yoluyla öğrencilerin güdümlü bir şekilde bu kelimeleri veya yapıları kendi metinlerine serpiştirmelerinin önü açılabilir. Lee (2008) öğrencilerin kendi metinlerinde beklenen söylem seviyesinde kelimeleri veya yapıları geri çağırabilmeleri için bunların okuma veya dinleme metinleri yoluyla bağlam çerçevesinde öğretilmesini önermektedir. Yine Ek E'de yer alan New Cutting Edge kitabında yer alan öğrencilerin metinlerini üretmeye başlamadan önce kelime entegrasyonu bölümü örnek olarak verilebilir. Konu ile ilgili birçok kelime tanıtıldıktan sonra öğrencilerden şikâyet mektubu yazarken kullanılabilecek diğer ifadeleri görebilmeleri için verilen modeli detaylı bir şekilde incelemeleri beklenmektedir. Buna paralel olarak, dilbilgisi, kelime imlası ve noktalama işaretleri ile ilgili becerileri geliştirmek için bazı aktiviteler de bu yaklaşımların herhangi bir aşamasına eklenebilir. Örneğin, süreç odaklı yazma yaklaşımının gözden geçirme ve düzenleme aşamalarında, öğrenciler daha etkili ve zengin metinler üretebilmek için bu alt becerileri pratik olarak uygulamaya koyabilir. Tür 
odaklı yazma yaklaşımında ise, öğrenciler model metinlerin dilsel yapılarını analiz ederken bahsi geçen alt becerilerin de pratiğini yapabilir. Çünkü öğrenciler dilsel yapıların, imla ve yazım kurallarının nasıl kullanıldığ 1 ile ilgili aşinalık kazanırsa, onların bu becerileri kendi metinlerine transfer etmesinin de mümkün olabilir. Ek F'de yer alan Elsworth ve Rose (1996) tarafından hazırlanmış kitaptaki etkinlikte olduğu gibi, herhangi bir dilsel yapının ön plana çıkarıldığı örnek metinler (bkz. Ek F, have/get something done) üzerine çalışan öğrencilerin bu dilsel yapılardan çeşitli alıştırmalar yaparak kendi metinlerinde yararlanabilmesi sağlanması mümkündür.

Yukarda bahsi geçen üç ana yazma yaklaşımından hangisi kullanılırsa kullanılsın, öğrenciler kendi metinlerini oluşturduktan sonra ürünlerini birbirleri ile takas ederek kendilerinin de üretmiş olduğu benzer metinlere sınıf arkadaşlarına geri bildirimde bulunabilir. Bu tarz bir aktivite ise dört ana becerinin yanı sıra diğer alt becerileri de tek aktivite ile tetikleme firsatı sunmaktadır. Bu da yazma öğretiminin yapıldığı yabancı dil sınıflarında, yazma sonrası etkinlik olarak düşünülebilir.

Bir sonraki bölümde yer alan İçerik Temelli Öğretim yoluyla yazma becerisinin diğer becerilerle ilişkilendirilmesine geçmeden önce bahsedilmesi gereken önemli bir yaklaşım da, hala geçerliliği olan dil öğretimine daha genel bir bakış açısı ile yaklaşan Tüm/Bütüncül Dil Teorisi (Goodman, 2005) olabilir. Temel felsefesi dil ve becerilerinin bir bütün olarak ele alınması olan bu teorinin vurgusu, gerçek deneyim ve öğrenenlerin bu deneyimlerden biriktirdikleri üzerinedir. Cavkaytar (2013), dil açısından zengin bir bağlamda hedef dilin öğrenilmesinin bir bütünlük yoluyla olacağını ifade etmiştir. Bu holistik teoride, tümdengelim süreçleri temel alınarak bir yabancı dilin anadil edinimine yakın bir şekilde öğretilebileceği/öğrenilebileceği düşünülmektedir. Buradan hareketle, bu yaklaşımın bütüncül bakış açısı ile dil öğretiminde parçalardan (dilbilgisi veya yalıtılmış ana/alt beceriler vb.) çok dilin bir bütünlüğü öne çkarılabilir ve yazma becerisinin geliştirilmesinde birçok alt becerinin de kullanılması sağlanabilir. Örneğin, Goodman (2005, s.32)'in de ifade ettiği gibi, hedef dildeki yazılı materyallerin (kitap, gazete, poster, vb.) incelenmesi ve benzer metinlerin üretilmesi, hem okuma-yazma gibi ana becerilerin kullanılmasına olanak sağlarken hem de kelime ve dilbilgisi gibi alt becerilerin kullanımını da tetikleyerek geliştirme imkânı sunabilecektir. 


\section{Yazma Becerisinin diğer Becerilerle İlişkilendirilmesi için bir diğer yol: İçerik Temelli Öğretim}

Yabanc dil sınıflarında etkileşimin doğal olabilmesini sağlayan yollardan biri öğrencilerin dört ana beceriyi de kullanabilecekleri bir ortam yaratılmasıdır. Bu sebeple, bütünleşik beceriler yaklaşımı yoluyla becerilerin tetiklenmesi ve kullanılması gerekmektedir. Oxford (2001), öğretmenlerin içerik temelli öğretimden (Content-based instruction) faydalanarak dört becerinin kullanılabilmesini teşvik edilebileceğinin altın çizmiştir. Bu makalenin ana hedeflerinden birisi yazma becerisinin öğretiminin diğer becerilerle nasıl ilişkilendirilebileceği olduğu için, bu bölümde, içerik temelli öğretim yoluyla yazma becerisinin öğretiminin nasıl yapılabileceği üzerinde durulacaktır.

1960'lı yıllarda yabancı dil eğitiminin sadece öğrenilen dilde alınması (immersion) ile gerçekleştirilen sınıflarda ortaya çıkmış olan İçerik Temelli Öğretim, Richard (2006)'ın vurguladığı gibi, içeriğin veya bilginin, dil öğretim çabası açık bir şekilde gösterilmeden, hedef dilin kullanımı yoluyla öğrencilere sunulmasıdır. Tematik konuların ve bu konulara gömülmüş dil becerilerinin aynı anda öğrencilere sunulduğu bu modelde, Briton, Snow ve Wesche, (1989)'a göre hedef dil sadece hedef tematik içeriğin öğrenilmesi için bir araç olarak düşünülebilir. İkinci veya yabancı dil öğretiminde de kullanılan bu yaklaşımda, içeriğin, konunun öğretimi için bir araç olması beklenmektedir. Bu noktada içerik, öğrencilerin ilgi alanları göz önüne alınarak öğretmen tarafından belirlenen bir bilim konusu, haber veya bir film bile olabilir çünkü burada amaç öğrencilerin sağlanan içerikle herhangi bir şey öğrenmesidir. İçerik yoluyla daha doğal bir şekilde dilsel yapıların odağa alınmadan doğal bir dil gelişim sürecini mümkün kılabilir. Shih (1986), İngilizce'nin ikinci dil olarak öğretildiği bir bağlamda, akademik yazma eğitiminin içerik temelli öğretim aracılığıyla desteklenmesinin öğrencilerin akademik dersler için yazmaları beklenen ödevlerin üstesinden gelebileceklerini belirtmiştir. Bunun sebebi olarak ise yazma eğitimi için kullanılacak içerik temelli öğretimin dinleme ve okuma becerilerine entegre edilmesi sonucunda ortaya çıan ürünün daha başarılı olmasını göstermiştir. Liaw (2007) ise içerik temelli öğretim ile öğrencilerin yazma becerilerinde analiz ve sentez yapma becerilerinin de geliştiğini bulmuştur. 
Yazma eğitiminin başarıya ulaşması için becerilerin bütünleştirileceği ve öğrencilerin yazma öncesinde dinleme ve okuma yoluyla elde edecekleri bilgileri tartışabilecekleri bir yaklaşım, öğrencilerin yazma becerilerinin gelişmesinin önünü açabilir. Bu da yazma becerisinin bağlam farkı olmadan sadece yazma yoluyla yapılamayacağını göstermektedir. Tutunis (2000), öğretim ve ödev öncesinde yapılacak okuma ve dinleme etkinliklerinin, öğrencilerin hem sözcüksel hem de sözcük dizimi gelişimine katkı sağlayarak birçok akademik yazma türünün edinilmesinde çok stratejik bir yere sahip olduğunu ortaya koymaktadır. Böyle bir bağlamda, yazma eğitiminin, planlı bir şekilde diğer becerilerin ilişkilendirilmesiyle güçlendirilebileceği açıktır. Ancak, içerik temelli öğretim yoluyla yazma eğitiminde öğrencilere verilen tematik materyallerin öğrencilerin duyuşsal ve bilişsel gelişimleri ile paralel ve uygun bir zorlukta olması gerekmektedir. Sonrasında öğretmenlerin yapması gereken öğrencilerin bu konuları öğrenmesini sağlayarak metin üretebilmelerini teşvik etmesidir.

İçerik temelli öğretim modeli oldukça teorik bir altyapıya sahip olmasına ve farklı bağlamlarda işe yaramasına rağmen yazma eğitimine uygulanması farklı planlamaları gerektirebilir ve ancak bu şekilde her bağlama uygun, bütün dil becerilerinin aktive edildiği ve öğrencilerin pratik yapmasını teşvik edebilecek bir model haline gelebilir.

\section{Sonuç}

Bu makalede, çeşitli öğretim materyallerinden ve bağlamlarından yararlanarak, yazma eğitimi yaklaşımlarından ve bu becerinin diğer becerilerle ilişkilendirilmesi yoluyla nasıl başarılı olabileceği tartışılmıştır. Bu tartışmalardan hareketle yazma sınıflarında yapılması gereken uygulamaların başında, hangi yaklaşım kullanılırsa kullanılsın bu yaklaşımın en verimli şekilde yürütülmesi ve öğrencilerin motivasyonlarının devamının sağlanması için onların dilsel gelişimleri de göz önüne alınarak aktivitelerin planlanması gelmektedir. Buna ek olarak, dilsel öğelerin öğretimi amaccyla oluşturulmuş önüretimli dile maruz bırakmak yerine hedef dilin özgün olarak kullanıldığ 1 materyallerin kullanılması da hedef ürün metinlerin gerçeğe yakın olmasını sağlayacaktır. 
Önceki bölümlerde bahsi geçen yazma becerileri yaklaşımlarının uygulanabileceği bağlamlar açısından Ürün, Süreç ve Tür odaklı yazma yaklaşım etkinliklerine bazı örnekler verilebilir. Elsworth ve Rose (1996)'un veya Hutchinson (1985)'un kitaplarından alınmış Ek G'de yer alan ürün odaklı yazma yaklaşımı çerçevesinde oluşturulmuş aktiviteler, İngilizce yeterlik açısından başlangıç seviyesinden orta seviyeye kadar öğrencilerin eğitim gördüğü ortaöğretimde bağlamında kullanılabilir. Ortaya çıkacak olan ürünler öğrencilerin dil yeterlikleri hakkında bilgi verirken aynı zamanda yazılı metnin kalitesini de yakından gösterecektir. Bu süreçte öğretmenlerin yapması gereken benzer dilsel yapıların ve işlevlerin yer aldığı model metinleri tanıtmak ve bir kalite kontrol danışmanı gibi hareket ederek öğrencilerin modelleri yansılamasını ve dönüştürmesini sağlamaktır. Süreç odaklı yazma yaklaşımı materyaline örnek olarak ise Cunnigham ve Moor (2005)'dan alınmış Ek H'deki yazma etkinlikleri gösterilebilir. Biyografi türünde bir metnin yazılması için planlama ve tasarlama aşamalarından son haline kadar birçok adım tanıtılarak öğrencilerin süreç odaklı yazma aşamasına aşina olmaları sağlanmıştır. Toplanmış verilerin analiz edilerek tasarlama yapan öğrencilerden model metin üzerinde çalıştıktan sonra farklı isimlerin biyografisini yazmaları istenmiştir. Bu, öğrencilerin ilgileri doğrultusunda bir seçim yapmalarına imkân sağlarken veri toplamayla başlayıp metne son halinin verilmesine kadar olan süreçleri de düşündürmektedir. Aynı kitabın 36. sayfasında yer alan aktivite Türkiye'de üniversite eğitimi alan öğrencilerin süreç odaklı yaklaşım ile hedef dilde yazma becerilerinin geliştirilmesinde kullanılabilecek bir örnek teşkil etmektedir. Son olarak, Ek I'da yer alan Farthing ve Pulverness (1994)'e ait etkinliklerde, ileri seviyede İngilizce eğitimi alan öğrencilere sunulabilecek tür odaklı yazma yaklaşımı etkinliği yer almaktadır. Bu etkinlikle öğrenciler birden fazla İngiliz gazete yazılarını analiz ederek bu modellerin türe ait özelliklerini ortaya çıkarması hedeflenmektedir. Bu analiz ve çalışma sonuncunda ise öğrencilerin türe özgü bir metin üretmesi beklenebilir.

Unutulmaması gerekir ki her yaklaşımın kendine özgü zorlukları vardır ve bir bağlamda verim alınabilecek modelin başka bir bağlamda işe yaramaması söz konusu olabilir. Bu farklılığın sebepleri arasında dersin hedeflerinden öğrencilerin hedef dil yeterliği ve motivasyonuna kadar çok fazla faktörden söz etmek mümkündür. Buradan hareketle öğretim bağlamını, dersin hedeflerini, öğrencilerinin seviyelerini veya farklı bileşenleri değerlendirerek en doğru yazma yaklaşımına karar verilebilir. Gerektiği durumlarda birden 
çok farklı yazma eğitimi yaklaşımı birleştirilebilir. Çünkü bu yaklaşımlar birbirini dışlayan bir özelliğe değil birbirini tamamlayıcı bir doğaya sahip olarak düşünülebilir. Özellikle, İngilizce'nin yabancı dil olarak öğretildiği ve sınıflarda öğrencilerin çok farklı derecede İngilizce seviyesine sahip olduğu Türkiye bağlamında, öğrencilerin belirli ihtiyaçları doğrultusunda yazma becerilerinin gelişmesi için diğer ana ve alt becerilerin de sinıfta kullanılması önem kazanmaktadır. Ancak, bazı öğrencilerin yazma becerisine karşı negatif tutumları veya bu beceriyi en az kullanacakları beceri olarak görmeleri süreçte motivasyonlarını kaybetmelerine sebep olabilir. Sonuç olarak, Byrne (1979)'nin önerdiği gibi, yabancı dilde yazma becerisi öğretiminin amacı ve dil becerilerinin bir bütün olduğu hangi kademede eğitim veriliyor olursa olsun en etkili şekilde tanımlanmalı, anlatılmalı ve yeterince pratik yapılmalıdır. Aksi takdirde, öğrencilerin oldukça kısıtlı pratik yapabilecekleri bir beceriyi edinmelerini ve geliştirmelerini beklemek çok gerçekçi olmayacaktır. $\mathrm{Bu}$ sebeple, uygun yaklaşımları ve diğer becerilerle bütünleştirme yollarını kullanarak verilecek yazma eğitimi farklı türde uygulamalar yoluyla yazma becerisinin kazandırılmasını sağlayabilecektir. 


\section{EXTENDED ABSTRACT}

\section{Revisiting Approaches to Teaching Writing and Integration of the Writing Skill with others in Foreign Language Education}

Erdem Akbaş

Erciyes University

This article presents a discussion on the major approaches to teaching writing and the integration of teaching writing into other major and sub skills by linking the discussion to a series of teaching contexts and materials, in particular to the context of teaching English as a Foreign Language. On the way to becoming independent and competent writers in the foreign language, language learners can benefit from the use of context-sensitive approaches by the language teachers to draw and maintain students' attention in writing activities. Considering the language learning process as a whole, for an effective communication, foreign language learners are supposed to master writing skill in the target language as well. Nevertheless, writing skill has been one of the most neglected skills in language education since it is likely to be accepted as hard by both language teachers and learners as evidenced in various context. With this in mind, one of the major aims of the article is to zoom in on the major approaches to teaching writing in foreign language education, English in particular, and discuss the integration of the skill with teaching other language skills through a range of examples. After reviewing the approaches to teaching writing by referring back to various teaching contexts, the article touches upon ways of integrating teaching writing skills with different types of activities.

Byrne (1979) clearly pointed that although foreign language learners seem to use relatively similar linguistic elements in producing written or spoken texts, written texts do own a highly contextual language use since these texts attempt to contact at a distance. In addition to this, the writers are expected to meet the requirements of a particular discourse community for which the text is produced and organize the text in a particular genre. Nevertheless, one 
of challenges experienced in teaching writing is partly related to decision on the approach teachers could adapt into their specific teaching context so as to gain the writing skill to their students. One of the major approaches to teaching writing is the product approach which deals with the production of a target text without focusing more on the process. The teacher only comes up at the beginning and end of the production by guiding students to the use of particular linguistic elements and structures in line with the model text. Badger and White (2000) suggest that there are four steps in the product approach leading to success in teaching of writing via this particular approach: (1) Getting familiar with the model text, (2) Controlled writing, (3) Guided writing and (4) Free Writing. The next major approach to teaching of writing is process writing with which both the learners and the teachers are quite active in the process of producing the text. This approach is primarily based on the idea of having a more student-centered approach focusing on the teaching of writing at discourse level with various process-oriented stages ranging from pre-writing activities and drafting to revising and editing. The last major approach discussed in the paper is genre approach, which basically follows the systematic guiding principles of a particular genre. As Kim (2006) states, the teachers could benefit from zooming in on the discourse characteristics and aim of a specific genre to support teaching of writing. Hyland (2002) points that this approach mainly deals with the modelling, negotiation with the teacher and construction of a text, leading to an understanding of a cycle in teaching writing.

In addition to these major approaches to teaching of writing, various scholars (i.e., Sanchez, 2000) suggest that the teaching of writing skill needs to be integrated with the teaching of other skills so as to reflect the whole language teaching, in which all skills are activated and interact. As is highlighted by Burgess (1994), such an integrated way of skills in language education is of great importance in terms of triggering learners to make use of both receptive and productive skills on the way of learning another language. Students seem to complain about the writing topic in which they have little or no knowledge but are asked to write on. In order to minimize it, a practical solution suggested by Jiang and $\mathrm{Du}$ (2006) can be followed to integrate writing classes with highly concentrated reading classes to support them. Unlike teaching writing in isolation, teaching writing skill integrated to other major skills appears to bring a case of spontaneous and natural communication into 
the language classroom. Activities with integrated skills could also pave the way for providing learners with the required discourse knowledge to be successful in using language. This is simply because the skills are not mutually exclusive, yet they have an intricate nature completing and supporting one another. Considering the ways of integration of writing skills into other skills, it is highly possible for teachers to decide on the most feasible writing approach by taking a range of issues (i.e., teaching context, objectives, interests and levels of leaners) into account and supporting the teaching process with other skills.

\section{Kaynakça / References}

Badger, R. ve White, G. (2000). A process genre approach to teaching writing. ELT Journal, 54 (2), 153-160.

Blasingame, J. ve Bushman, J. H. (2005). Teaching writing in middle school. Upper Saddle River, New Jersey: Pearson.

Briton, D. M., Snow, M.A., ve Wesche, M. B. (1989). Content-based second language instruction. New York: Newbury House.

Burgess, J. (1994). Ideational Frameworks in Integrated Language Learning, System, 22(3), 309-318.

Byrne, D. (1979). Teaching writing skills. London: Longman.

Cavkaytar, S. (2013). Tüm dil yaklaşımı (whole language). M. Durmuş, A. Okur (Der.), Yabancılara Türkçe öğretimi el kitabı içinde (s.95-100). Ankara: Grafiker Yayınları.

Celce-Murcia, M. ve Olshtain, E. (2000). Discourse and context in language teaching. New York: Cambridge University Press.

Cunningham, S. ve Moor, P. (2005). New Cutting Edge (Upper Intermediate-Student's Book). London: Longman.

Elsworth, S. ve Rose, J. (1996). Go (Student's Book 1). London: Longman.

Farthing, M ve Pulverness, A. (1994). The Macmillan short course programme: Level 3 reflections: Student's book. London: Macmillan

Gao, J. (2007). Teaching writing in Chinese Universities: Finding an eclectic approach. Asian EFL Journal, 20(2), 285-297.

Goodman, Ken. (2005). What's whole in whole language: $20^{\text {th }}$ anniversary edition. Canada: RDR Books

Harmer, J. (2007). The practice of English Language teaching. London: Longman.

Hedge, T. (1988). Writing. Oxford: Oxford University Press. 
Hedge, T. (2000). Teaching and learning in the language classroom. Oxford: Oxford University Press.

Hocaoğlu, N., ve Ocak, G. (2019). Challenges of writing English according to unıversity students' views. European Journal of English Language Teaching, 4(4), 49-69.

Hutchinson, T (1985). Project English 1. Oxford: Oxford University Press.

Hyland, K. (2002). Teaching and researching writing. London: Longman.

Hyland, K. (2003). Genre-based pedagogies: A social response to process. Journal of Second Language Writing, 12, 17-29.

Jiang, C. ve Du, H. (2006). Integrating Reading and Speaking with Writing in College English Teaching, Sino-US English Teaching, 3(3), 37-40.

Johns, A. M. (1995). Genre and pedagogical purposes. Journal of Second Language Writing, 4(2), 181-190.

Johnston, H. (1996). Survey review: Process writing in coursebooks, ELT Journal, 50(4), 347-355.

Kim, M. (2006). Genre based approach to teaching writing. HPU TESL Working Paper Series, 4(2), 33-40.

Lee, S. H. (2008). Beyond reading and proficiency assessment: The rational cloze procedure as stimulus for integrated reading, writing, and vocabulary instruction and teacher-student interaction in ESL. System, 36, 642-660.

Liaw, M. L. (2007). Content-based reading and writing for critical thinking skills in an EFL context. English Teaching and Learning, 31(2), 45-87.

Myskow, G. ve Gordon, K. (2010). A focus on purpose: using a genre approach in an EFL writing class. ELT Journal, 64, 283-292.

Nunan, D. (1991). Language teaching methodology. Hertfordshire: Prentic Hall International

Oxford, R. (2001). Integrated skills in the ESL/EFL classroom. ERIC Digest, ED456670. 15 Mart 2020 tarihinde, https://eric.ed.gov/?id=ED456670 adresinden erişildi.

Raimes, A. (1991). Out of the Woods: Emerging Traditions in the Teaching of Writing, TESOL Quarterly, 25(3), 407-430.

Richard, J. C. (2006). Communicative language teaching today. New York: Cambridge University Press.

Sanchez, M. A. A. (2000). An approach to the integration of skills in English teaching. Didactica (Lengua y Literatura), 12, 21-41.

Shih, M. (1986). Content based to teaching academic writing. TESOL Quarterly, 20, 617-648. 
Swan, M. ve Walter, C. (1985). The Cambridge English course (Student's Book 2). Cambridge: Cambridge University Press.

Tabak, G. ve Göçer, A. (2013). 6-8. Sınıflar Türkçe dersi öğretim programının ürün ve süreç odaklı yazma yaklaşımları çerçevesinde değerlendirilmesi. Ahi Evran Üniversitesi Kırşehir Ĕ̆itim Fakültesi Dergisi, 14(2), 147-169.

Thaqi Jashari, L., ve Dagarin Fojkar, M. (2019). Teachers' Perceptions of Developing Writing Skills in the EFL Classroom. ELOPE: English Language Overseas Perspectives and Enquiries, 16(2), 77-90.

Tribble, C. (1996). Writing. Oxford: Oxford University Press.

Tutunis, B. T. (2000). Content Based Academic Writing, The Internet TESL Journal, 6 (7). 15 Mart 2020 tarihinde, http://iteslj.org/Articles/Tutunis-ContentBased.html adresinden erişildi.

Walker, J. P. ve Sampson, V. (2013). Argument-driven inquiry: Using the laboratory to improve undergraduates' science writing skills through meaningful science writing, peer-review, and revision. Journal of Chemistry Education, 90(10), 1269-1274.

White, R. ve Arndt, V. (1991). Process Writing. London: Longman.

Zeng, D. (2005). The process-oriented approach to ESL/EFL writing instruction and research. Teaching English in China, 28(5), 66-70. 


\section{Ekler}

\section{Ek A. Yazma ve Okuma becerilerinin bütünleştirilmesi örneği (Farthing} ve Pulverness, 1994, s. 1, 56-57)

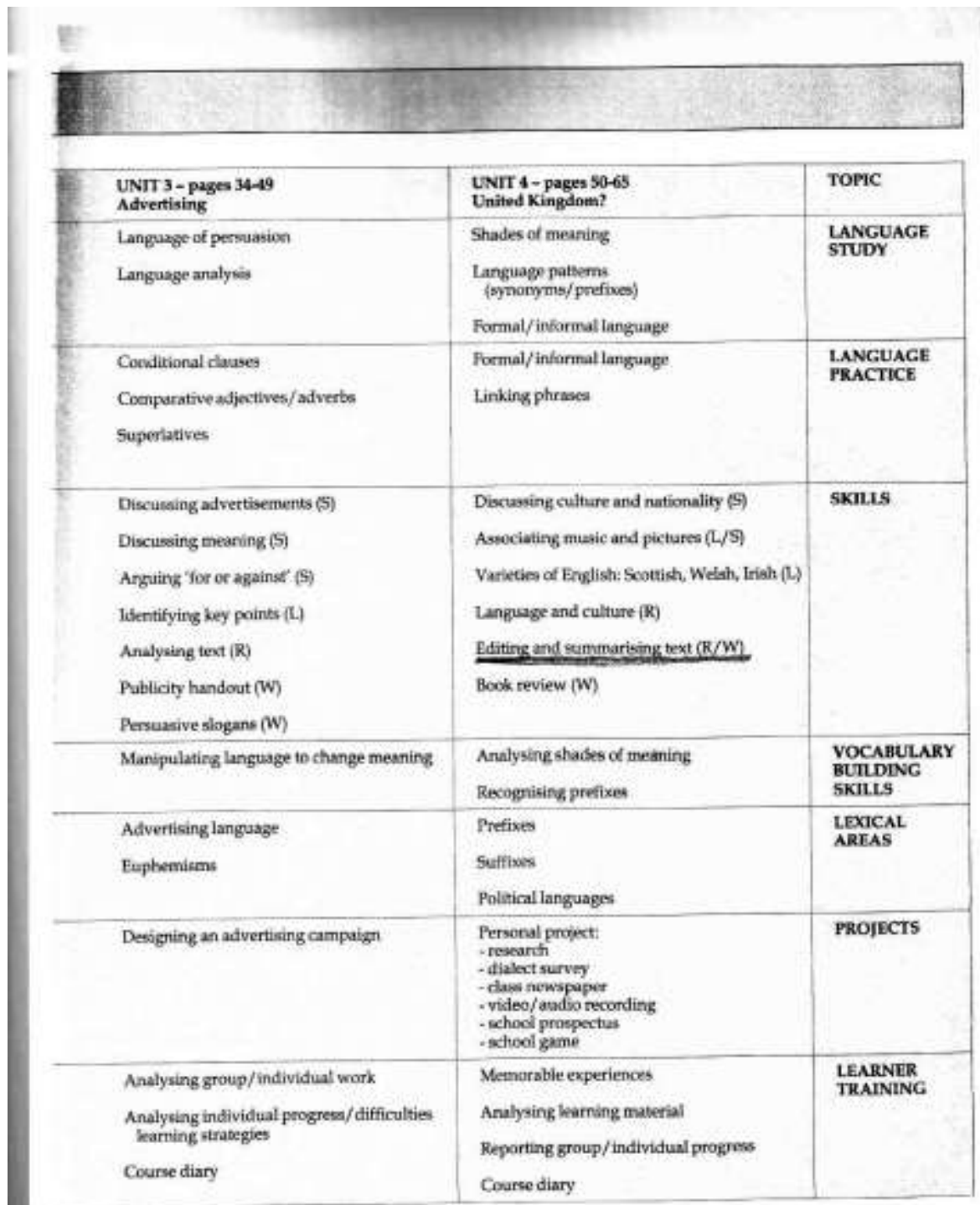


Yabancı Dil Eğitiminde Yazma Eğitimi Yaklaşımlarının Gözden Geçirilmesi ve Yazma

Becerisinin Diğer Becerilerle İlişkilendirilmesi

\section{SECTION 4}

\section{LANGUAGE AND CULTURE}
O I tum many dofferent Laeguages ame represe unted in wout Ltass?
31 Irue many cif these ianguages bafcury, wh ethnir groujk

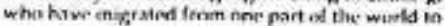 sinsher, et is Remaliand Cantemese in Hentain

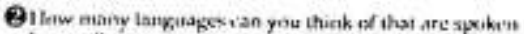

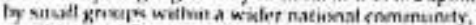

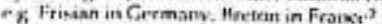

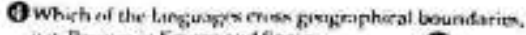
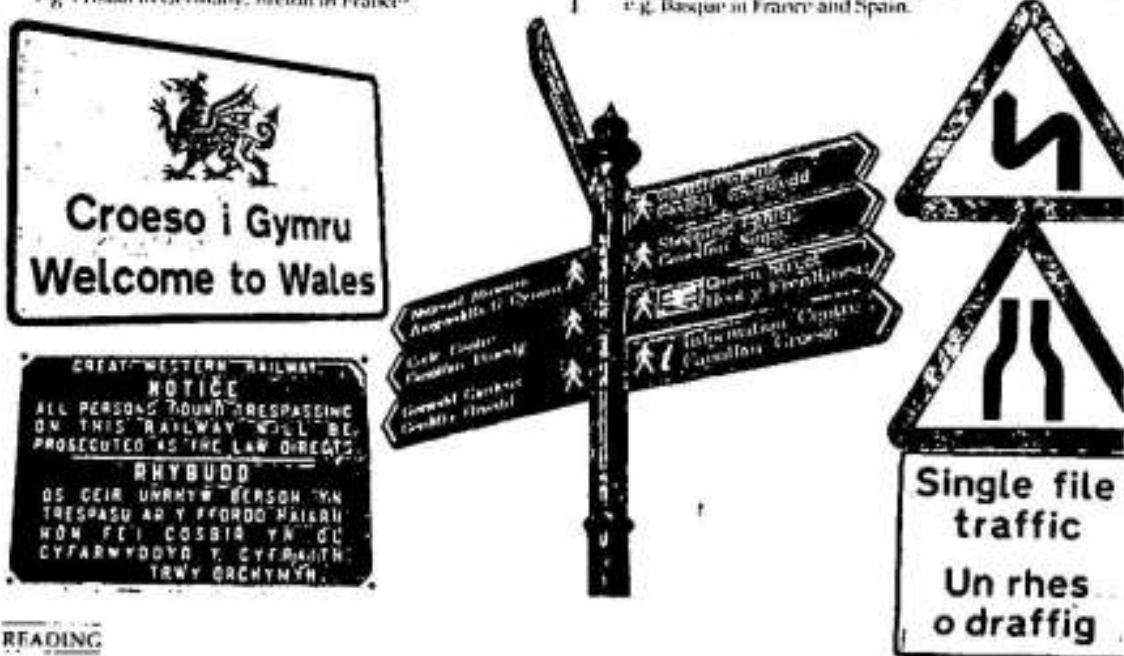

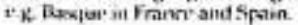

RTADINĞ

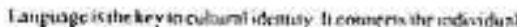

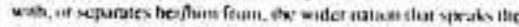

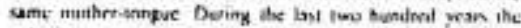

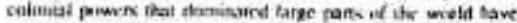

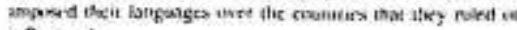
enluenced.

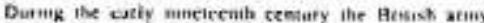

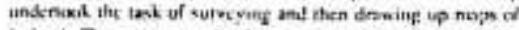

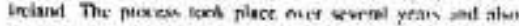

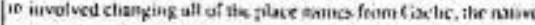

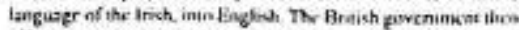

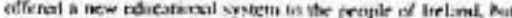

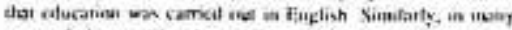

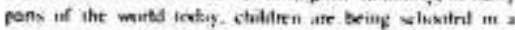

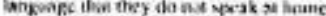

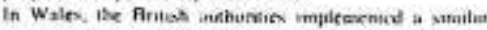

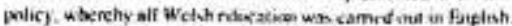

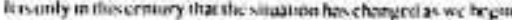

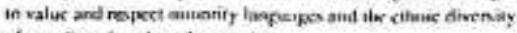
in of a meltiecultursl unders wacicty

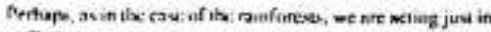

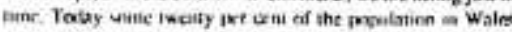

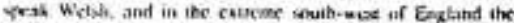

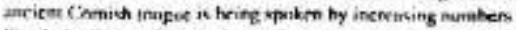

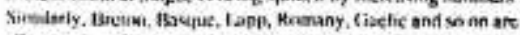

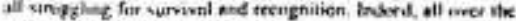

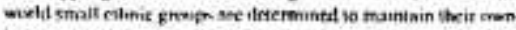

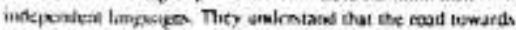

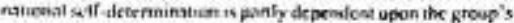
4. aluluy to vov and procere ils num langease

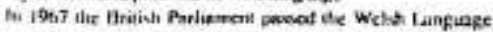

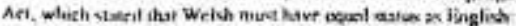

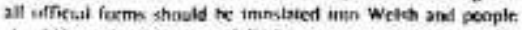

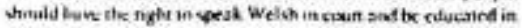
the Wowlo tannesper.

This bad uin alway been ithe rax, as the fallowing

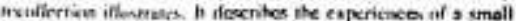
bry wher was yed varting seterel. His veacher was tinglish and hor mwellet-lisipge wan Welds.

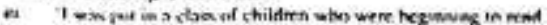

156.

Ris. 
Frglivh 1 enild resd welvh yune wetl. The ond swon werk

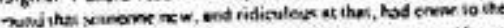

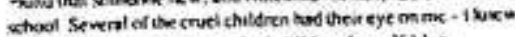

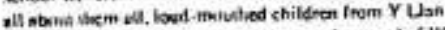

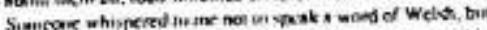

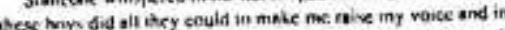

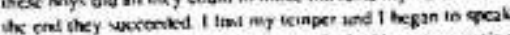

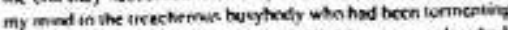

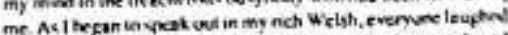

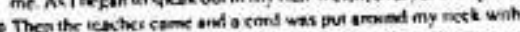

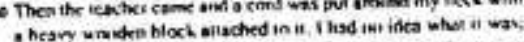

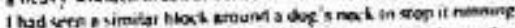

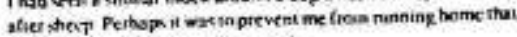
the Hach was hune arteund niy inct

As bys is won midsay, the sime in he released The

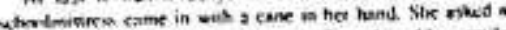

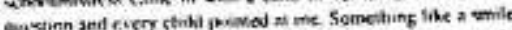

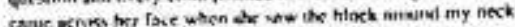

She pulled off the Maxk ead then I underveod that it was fo

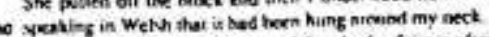

Th- bilack whe anword my neck hundreds of aimes afver thai Dhis is bow in wes done- - then a child wa keand watering a mons of Welyh, the senetice was to be init, then tie blick was

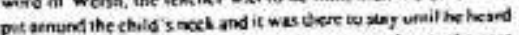

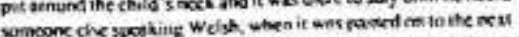
pon child at the end nt the day the one tho wes westing $t$

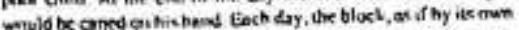

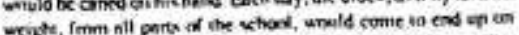

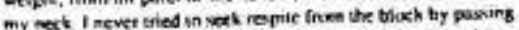
it on snocher $1 \mathrm{~km}$ w enahing sboul the crinciete of the thing.

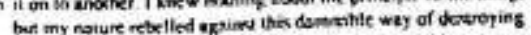
the fiunation of a child's charoced. To kesch a thild 10 spy on

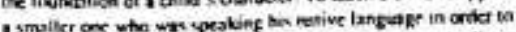

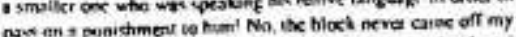

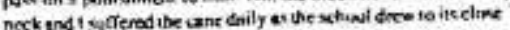

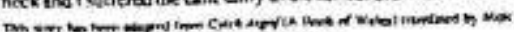

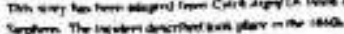

\section{LANGUAGE PRACTICE}

6 Working in pairs. prepore sualien' senes to show how the

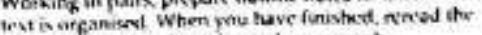
wat and write hadirege for each paragraph

GCimpan wour nutine and paragraph heodergs with

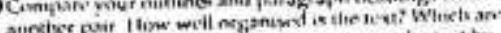

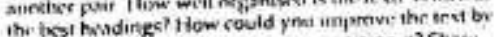

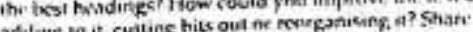

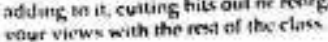

Q la net men: than Uurty wardt, wher a wimmary nt itw tom then is to the wall anit enenpare your sumeiary with

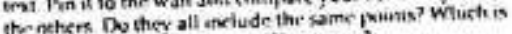

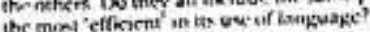

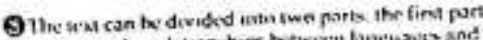

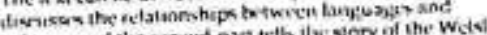
cutten a and the seound part tethe ilwesery of the Wist

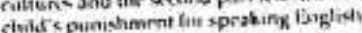

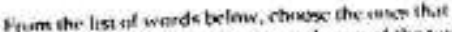
derrite the tyress al whiting; en eseh part of the wext

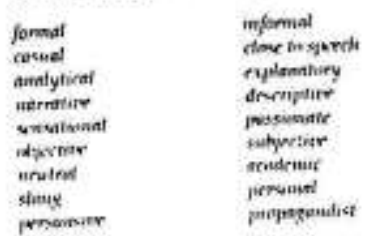

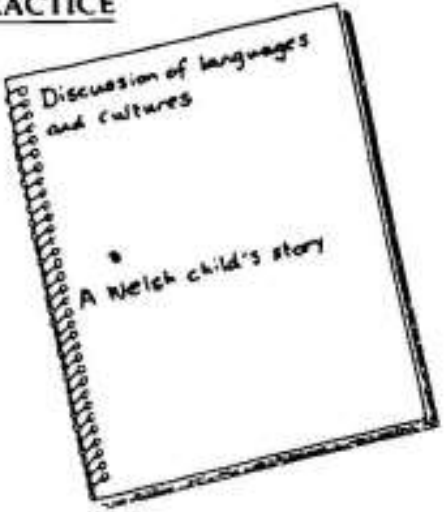

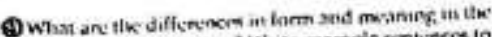

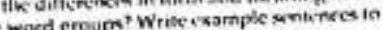

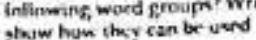

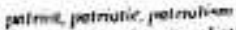
ueliant netinnel motasualistic celfare cutiurn

Ahime, Altwicty Annoutyer Lenxuistis

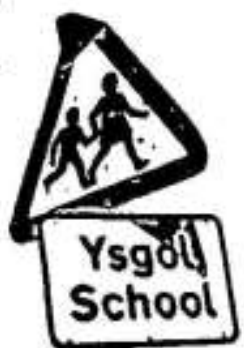




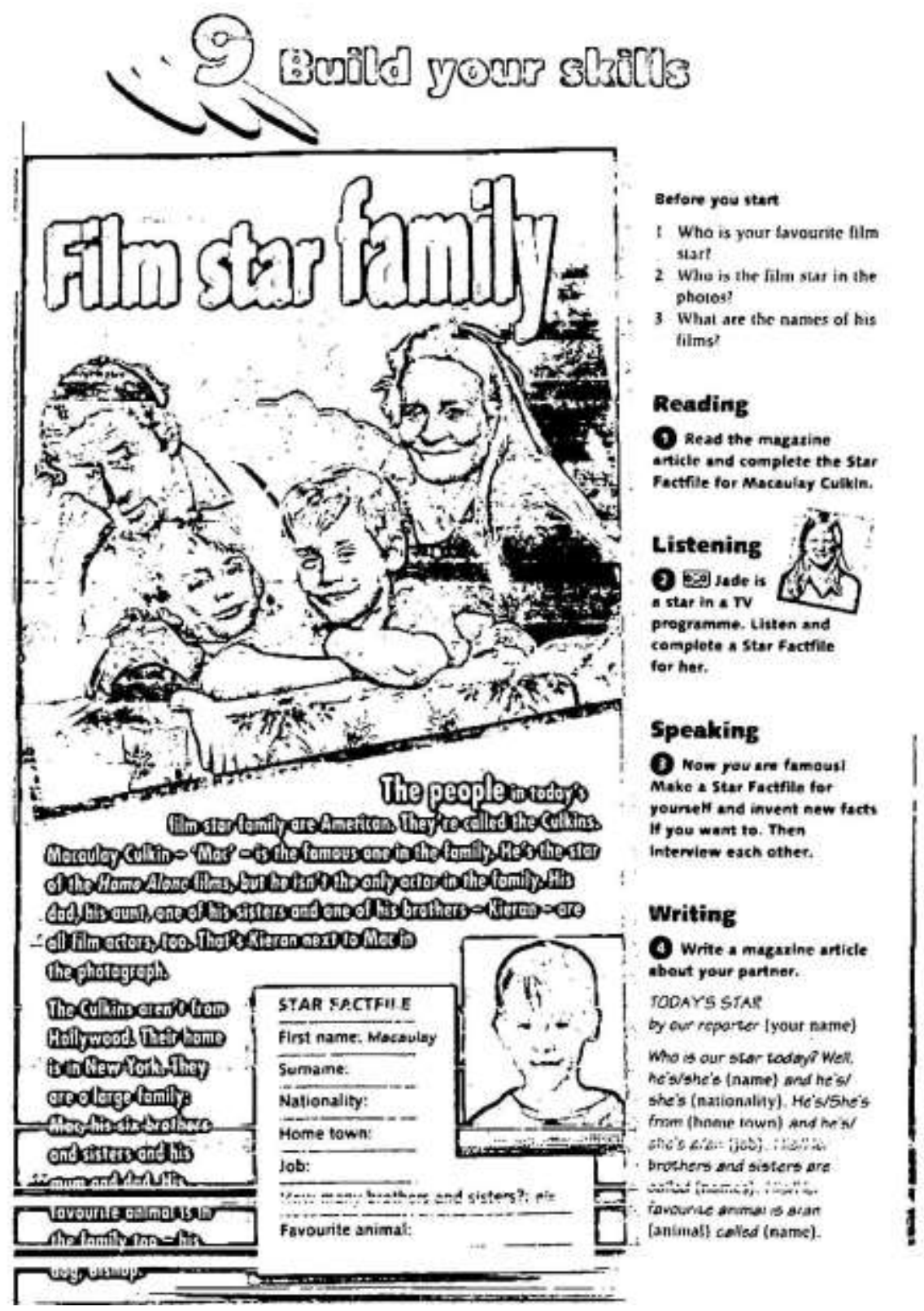


EkC. Tür odaklı yazma etkinliği- İş başvurusu mektubu (Swan ve Walter, 1985, s. 48-49)

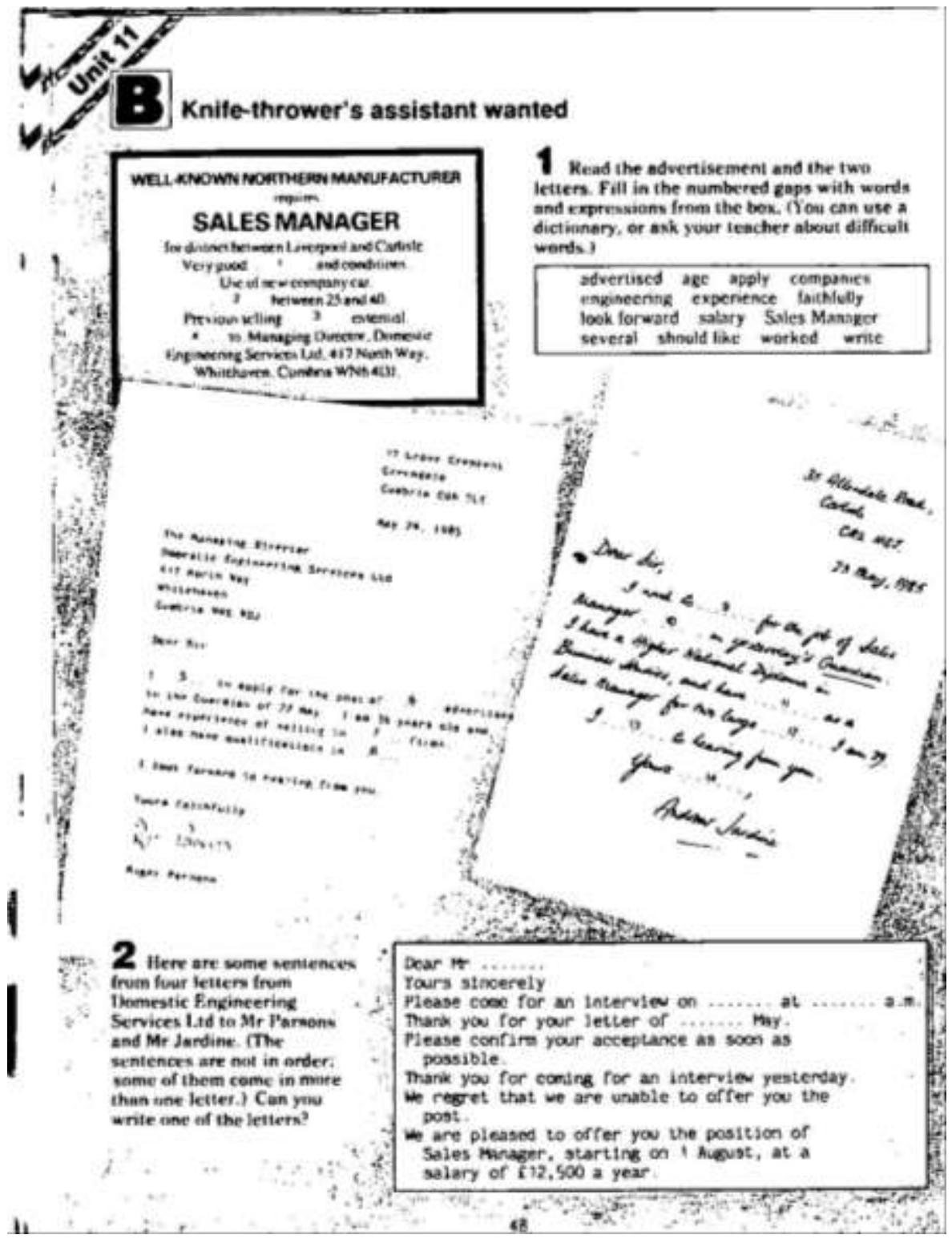


Yabancı Dil Eğitiminde Yazma Eğitimi Yaklaşımlarının Gözden Geçirilmesi ve Yazma

Becerisinin Diğer Becerilerle İlişkilendirilmesi

Read the advertisements with n dictionary.

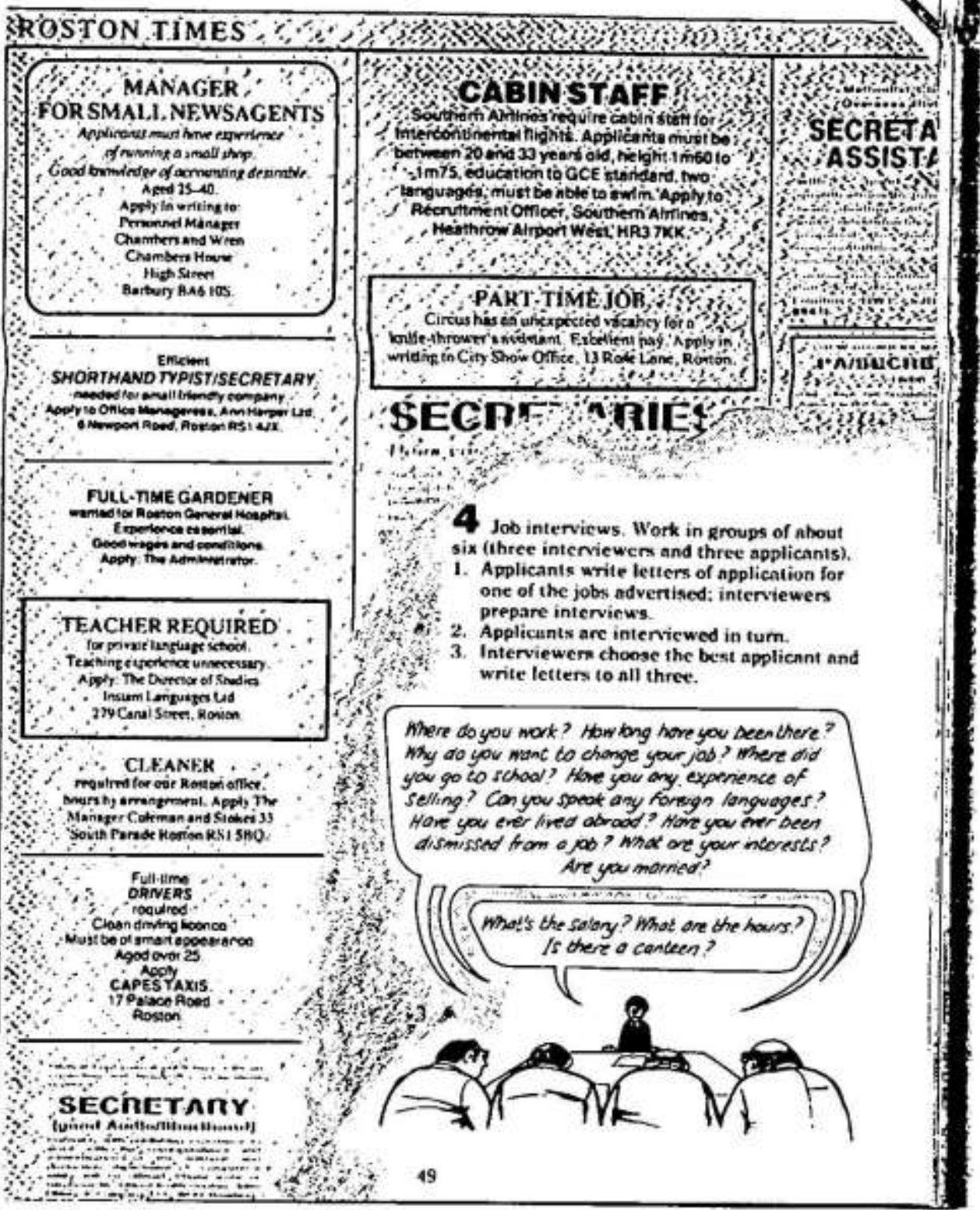




\section{FINAL PROJECT}

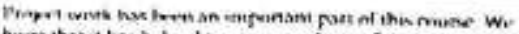

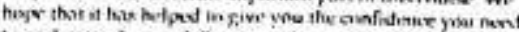

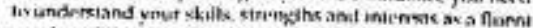

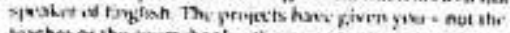

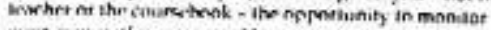

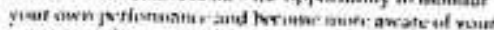

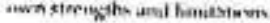

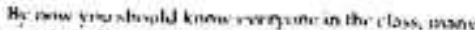

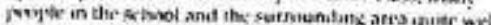

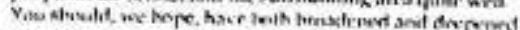

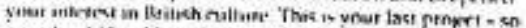

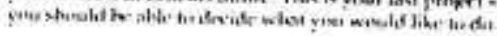

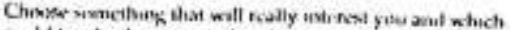
mild tored valec in you alier the mirse his finished

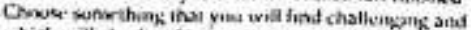

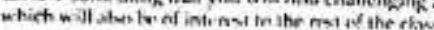

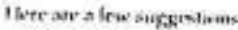

\section{YOUR OWN RFSEARCH PROJECT}

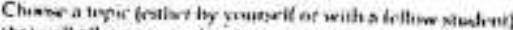

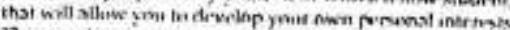

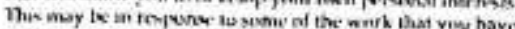

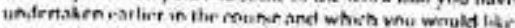

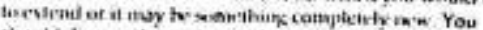

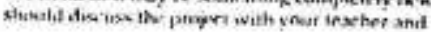

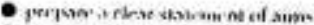

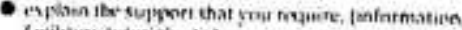

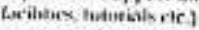

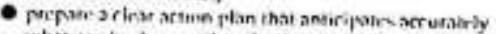

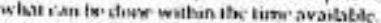

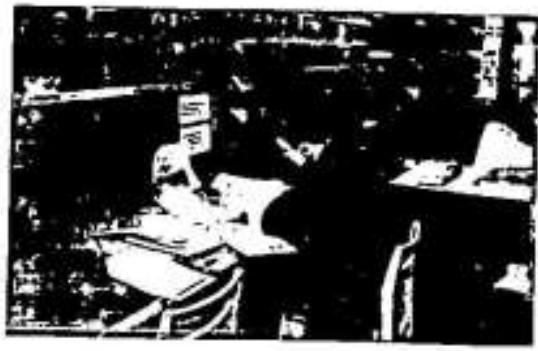

\section{DIALECT SURVFY}

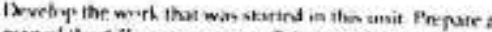

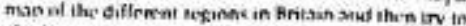
ac.

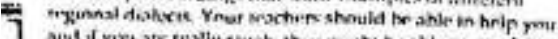
aind if yie atr wally stuck. ther mitht ke ahle mopras in

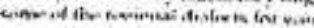

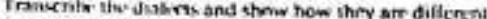

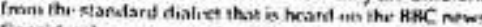

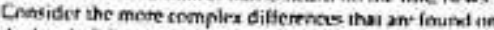
ilu' howi of the rax'sbulary snd the g,ramnia

Lreaniple.

$$
\begin{aligned}
& \text { BACSiandand Bequenal Dialse: } \\
& \text { llad-iemperad Crusty (O) fonthinges } \\
& \text { I was I wen (Weaci Cimurary) } \\
& \text { That is his Ras is hem (Keis) }
\end{aligned}
$$

Design a quastivetnate to find ent how the Beitish fezerd

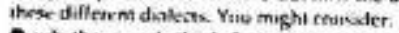

- whither perpipt thenk that wikne arrents ane mote cormet than athers

what the schunle shnould tor krathing

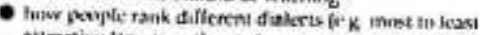

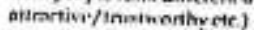

- how the wievikion and wievision advertisemems inake use of ditfinent tegionst dialors.

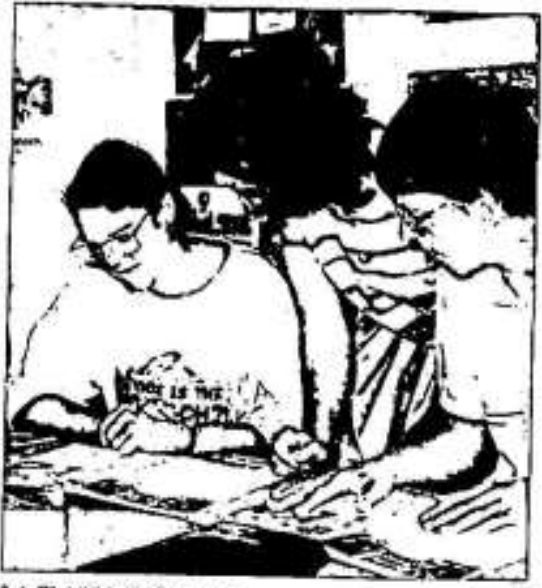

3A CI.ASS NFIYSH'AIIR

I'mpare att enisol course ncuspupret fot the sched that inclites

- schiand max

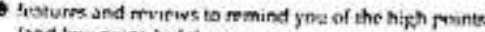

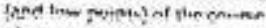

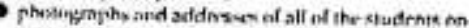
vaut churse

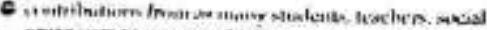
onganecers as you ran evilain

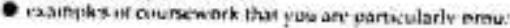


Yabancı Dil Eğitiminde Yazma Eğitimi Yaklaşımlarının Gözden Geçirilmesi ve Yazma Becerisinin Diğer Becerilerle İlişkilendirilmesi

\section{Ek E. Dinleme becerisi ile ilişkilendirilmiş yazma aktivitesi (Cunningham and Moor, 2005, s. 46)}

module 4 The mind

\section{Writing \\ A formal letter}

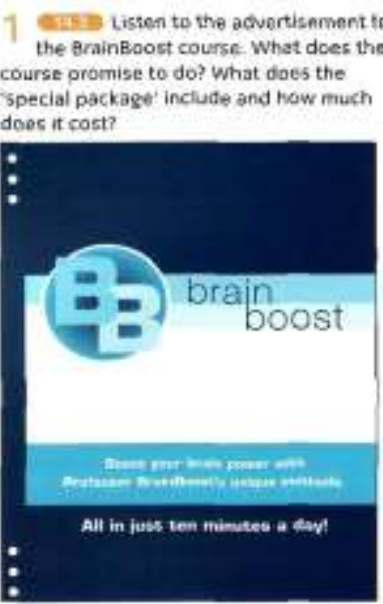

2 Phillip buys the Braindoost course, but is unappy with it, and telephones the compeny to complain. Read some of the things he says to Mr Mortin, the mariager of arainisoost. Why is he unhappy wish what

he has received?

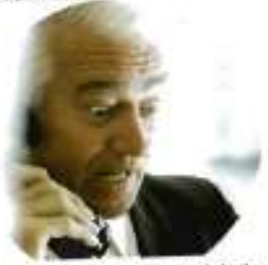

You cold me r'd get it in forty-eight boark. but actually it took neartly throe weeks.

Your ad said that the exercises only take ien minutes a day, but Ive worked ont that they toke mone bike two bours a day.

And asother thing - J jost cannet understand how you cas say these boring exercises are cajoysble!
3 in Phillip is asked to put hia complaint in writing reac his letter snd underline the words he uses to make his complaints from exercise ?

Mr David Martin

12 Priary Terace

Beain Hoost

PO Bos 327861

B Jauuary

Dear Mr Martin,

Following our teleptautu conversatice yesterday. 1 am wniting to bomplain abost the 'Bruia Booat special paokage' which 1 marchased from your compeny over the libternet sis weeks age.

I am dissatisfited with the produet and service that i hare redetred for a mumber of reasans. Firsty havine pavd C3.95 prsiage and packing $f$ was lold that I wauld recelve the course wit in furty-sigh! hour witeress in fact it took abmost three weeks to xrrive.

Your edverisumest promised thas ile neveviary esercises would be enjoyable and take only ien minules a day ta complena. However, I have caiculast that in order ta conequlete the exercises suggented, is would take clower fo two louss a day . Furihermove, I rotally fall is compechand bow you can describe these tedions excerises as enjoyable, of sleverst that they will 'opes ep your ironpioation'.

Finally. I hawt diacovered thas the vitaraint and CDs which you deucribs as 'unique' can be purchaend in my lacal supermarket for half the prive that you cbarge.

1 am of the opinion that your coarse has been a total waste of botb my time snd money, and demand $t$ camplete refugd of eversthing thet $I$ innev goid, incluciing postrect snd packing

Youns siocersly,

Philipo Mortimer

Psillip Mfornamer

in what ways are the grammar and vocabulary Phillip uses in the fetter different from what he says?

c Find more formal words and phreses in Phillp's letter that mean the following.

1 hfter (paragrapin 1$)$

2 buy (I)

3 unhappy (2)

1 but uctuoliy (2)

6. I have wrorked oat (3)

7. 1 just cannot underatand (3)

B. Ithink (S)

to do (3)

4 Underbine any other phrases in the letter that might be useful in a letter of complaint.

5 Loak at page 139. Imagine you bought one of the language courses. Thirk of at least four things that werk wrong White a letter complsining to the company and asting for your money buck 
Ek F. Yazma aktivitesi için ön plana çıkarılan dilsel yapı (Elsworth ve Rose, 1996, s. 47)

\section{have/get something done}

Mead about how to keep yeur brain healthy Can you think of any ather ideas?

\section{Five ways to keep your brain healthy}

\section{1 in we?}

We all know the saying tessithy hody. healthy mind Qily fish ike wimon and fund. along mith levil and vegrlables, provide crsential vilamins to keep ynur braut pouisg and lis

\section{2 treacte}

Rrgolat racese increasc the circulasion of blnod to your brain making il more ellocieni "f mu huven't excicised regulariy beforc, gct mou blond neessure theched to make vute pout bear is licalthy.

\section{3 txerdse reur troth too}

luss lise your body your buasn heris so herp fit. Do crosswsirds, read beeks. Ins and develop your momory with special esercises

\section{Arotd siress}

wr all know that when we have tap much to dea we seart to fnrket thirga. Take bresks and make time to relas

\section{5 cer vour beartag chitched}

Hearing low can seribubly anlerlen. with nurmasy. wo id you think rau might have $A$ problem, have your eass iesied righs now

1. Compre these sentesces from the text ahove. Wha does the testing in each one? What is the difference in the vero loem? West pour memory with speciol eneresies. Wove your eors tested nigh non

find another exomple of the second type of sentence in the tert above

2 We also use get in thas construction it is mere intormal than hove, but the meaning is the same Get your hearing checked

Pead Language summary $D$ on page Ia?

\section{Practice}

write sentences to describe these pictures.
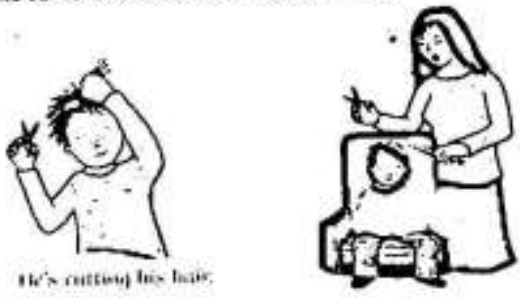

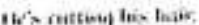
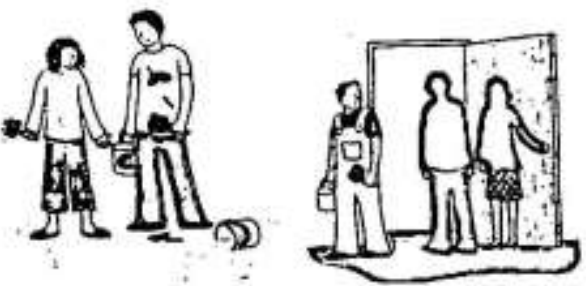

Look at the business cards below. What can you have done at each of the places? Write three sentences lor each.

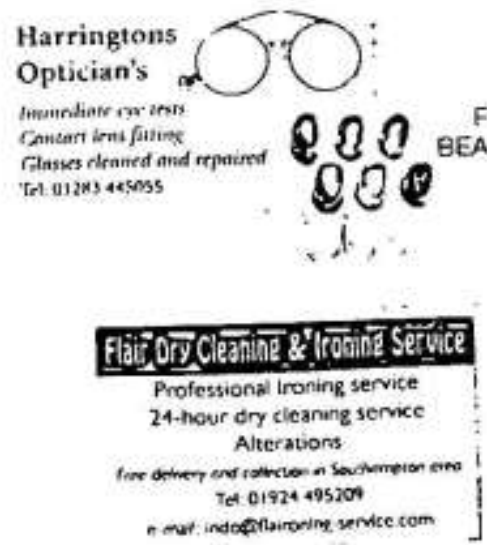

Listen to sameane phaning one of the businesses bove, which business is the customer phoning? Which service is he asking about? With a partener, invent four similat dialoxues using the cards above. 
Yabancı Dil Eğitiminde Yazma Eğitimi Yaklaşımlarının Gözden Geçirilmesi ve Yazma Becerisinin Diğer Becerilerle İlişkilendirilmesi

Ek G. Ürün odaklı yazma yaklaşımı etkinlikleri (Elsworth ve Rose, 1996, s. 53; Hutchinson, 1985, s. 76)

\section{COMMUNICATE}

5 In pairs, act out the canversation in a caft.

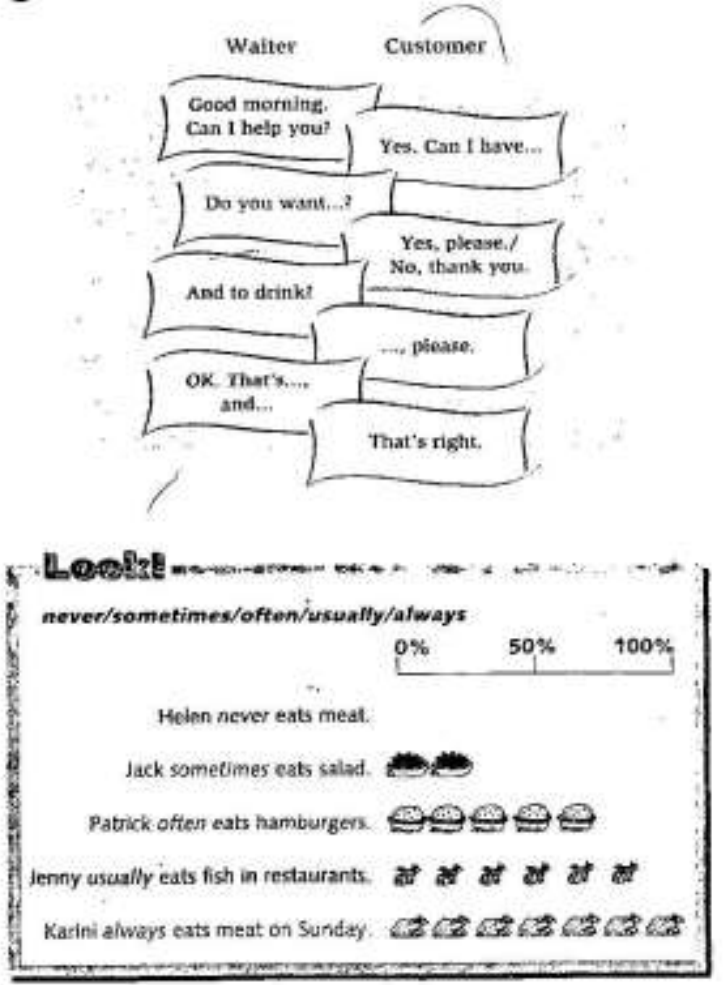

Say what they have for breakfast.

$$
\begin{aligned}
& 0 \% \quad 50 \% \quad 100 \% \\
& \text { Helen (toast and hutten } \mathrm{ES} \mathrm{B}
\end{aligned}
$$

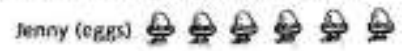

$$
\begin{aligned}
& \text { Patrick (cheese) }
\end{aligned}
$$

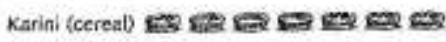

$$
\begin{aligned}
& \text { Jack (corcal) exts }
\end{aligned}
$$

Helent often has toast and butter for broaifask.
7. Talk about what you have for breakfast, lunch and dinner.

- What do you usually bave for breaktast?

OI usoally have ...... . How about you?

(8) Read about Jack's favourite sandwich.

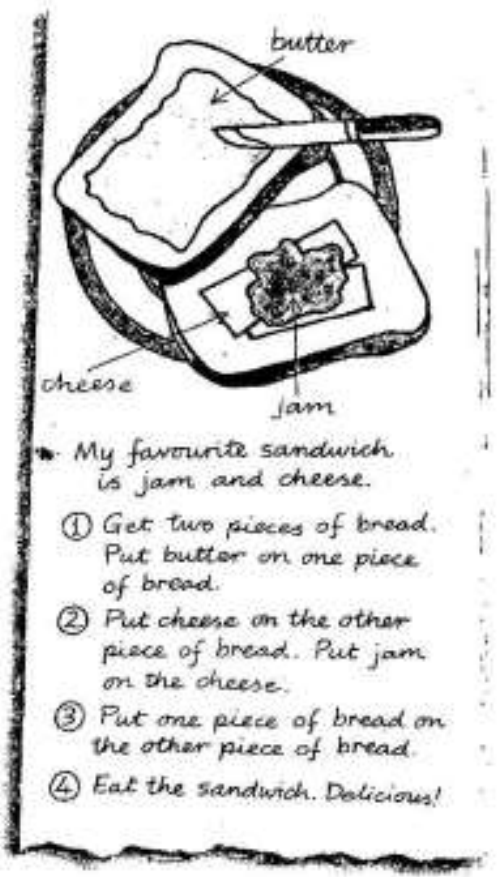

Write how to make your favourite sandwich. Use Jack's sandwich ns a model.

10 Now tell the class about your favourite sandwich! 


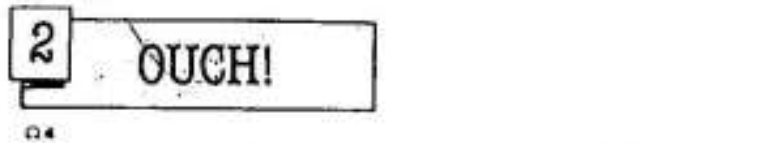

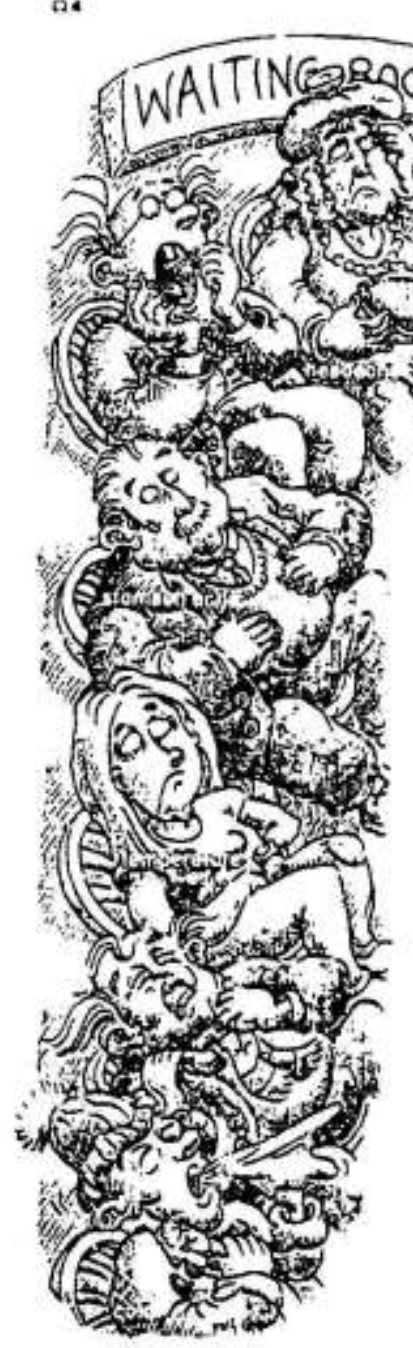

\section{Exercises}

1 What's the matter?

a what was the inavier with them? as listen and witie like thus Neme What was the matter?

b Now ask and answer

\section{Example}

A What was the marter with Bow? 6 He rad a neadache

2 Loot a: Tony's mother's intter to hes redcher ot pape 74 tony is lalkung to another jeache Coindere the conversation

where ..... You last meek. Tony? 1 - $-\ldots-11$ Q.? What ..... tha matier? 1 .... bu

.... you al ingli now? Yes thank you

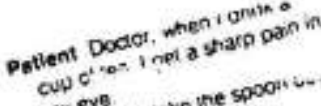

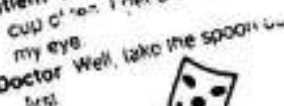

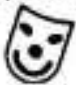

3 trere are some more letrers Make the pugls' conversations with the teachet

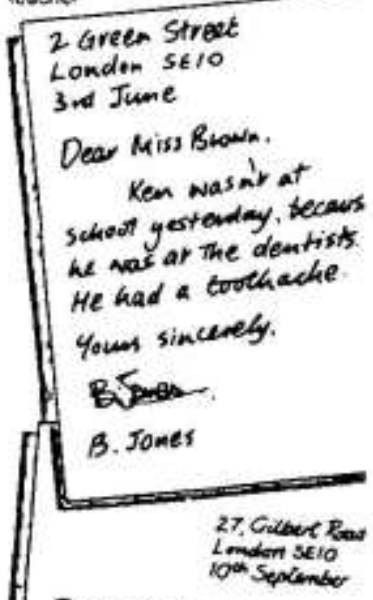

Dear Mos Bream,

Clave seavic at serand cost Frdey, beciuce she was ill stre had o anecative and $a$ sare arac.

Hous senarely 5 moles

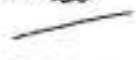

\section{Your project}

\section{A letter to the teacher}

Was anyone Al in yout giosp last noek?

1 Wrie their letter to the reacho 2 Sickit imo your Propect Book 


\section{Ek H. Süreç Odaklı Yazma Yaklaşımı Etkinlikleri (Cunningham ve Moor,}

\section{5, s. 12-13,36.)}

\section{module 1 Past and present.}

\section{Writing \\ Planning and drafting a biography}

1 a when you write an impertant letter or composition, do you plan it before you write the final draft? What do you da?

b head the ideas belaw for planning and drafting a piece of writing Which do you find most usetur?

\section{Four steps to better writing}

\section{Preparing and gathering information}

Give yourse if a time limst to brainstam all the sopics you might inchude. ond to check information. Moke brief notes by each topic. cet as much information as you can on paper (a quald search on the Internat may belp you heres. Dan't womy too much obout the argonisation of your lacas at this point - you can sluvays change things loter.

\section{Seructuring}

Think about the order in which you will present the information. te passibje, check with enother student or your nocker to see if they bink. your onder is deoe and logieal.

\section{First draft and feedback}

White a first droft. givng yourself a time limit to complete the text. show your first dran to ancehes student or waur teachat. hsik them to tall you about things that are unclear, or it there are any importont mistakes. Head the drak yourself. Am there batser monds ex phrasen you tould use to express your ideas?

\section{Final draft}

Use the feedbock to prepare the final draft. Then proofread your work (Chock, it for simple eirnts, spelling mistakes. etc). If you're hoppy with what grou have writren, you howe nalshedt

2 a. A student is writing a biography of the acter mowan Atcinson. fook at notes $A$ and $B$. Which stages in exercise 1 b do they lllustrate?

b into which paragraphs in B should the information in A. go?

3 Read the firsz draft of the biography (C). The writer is checking spelling (sp) and punctuatson (p), and has marked the points heishe is unswre of. Which are correct? Which are wrong? Correct them.

4 a Use the 'lour steps' in extreise ib to wnte a biograghy of one of the people belaw

- My sporting hera

My grandiarherimother

- My oldest and dearest triend

- Miy favouster finestorientertuiner

- The most ecrintic person I know

b As you check your Eirst draft, pay atention to the verb torms you studied on page ID. Can you use any of the past and present time phrasos from page 9 ?
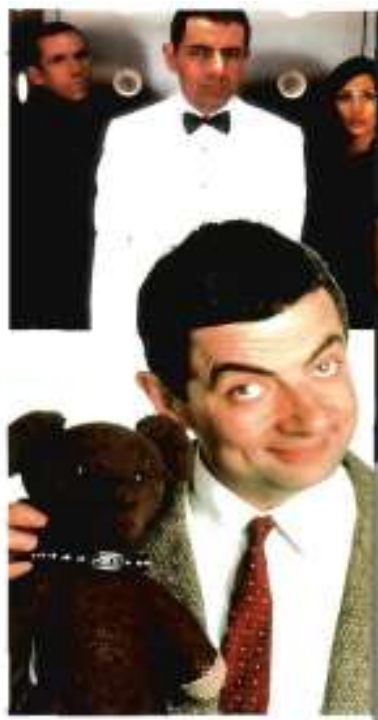

A

Mamid to Sornetra Soniry, a traksup artiest tso chikesn bin gad Lit

b Rerely wen in public, aimes nover give miteviost

c. Alicraled Newcable and Codond Univecelies, where te aperared in sewaral studert productions

d. Born in nexth-test of england, 197\%

c Siny at schooh - had ablur to make oher studerth laugh

$f$ is the fousth mest resagrices Britidi person it the wasl4

9 Fint fim sppeararce Mil89 - Never Sor Naver Masin:

h Doveloped character of Mr Bean in early $1990 \mathrm{cos}$

1 World-faroous a Mr Bean

I) Mary fiim robe inclading Intrmi Engith and Four weddinge and a funerall.

(B)

Paragraph tw what he's fumces for Paragrapbi 2 eath V/e and edacadion Paragaph 7; earli caren ind devolopment of wr Btan characker

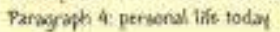




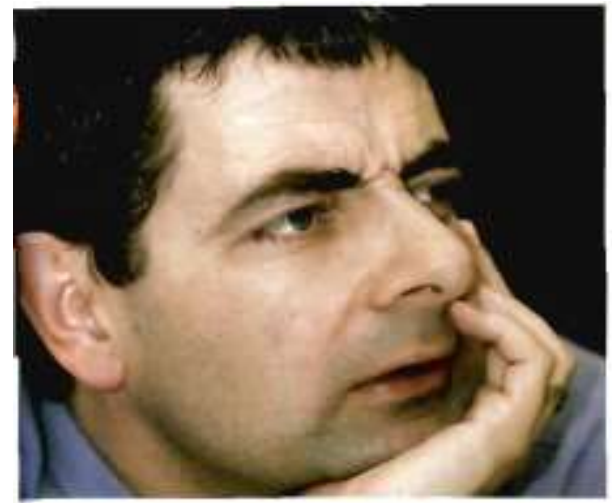

○

\section{Rowan Atkinson: a Comic Legend}

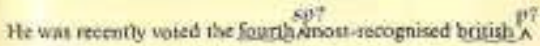
gernon is the workd - bat while miltines know him as the rubber-faced me Beas Nmech kess is knowa about the tife of Momun Atkimson, the actar who sreated the charncter, and ntw hat played masy other TV and film roles including the nervoun pocisin- Four Waddiogs and a Fianerar Wad the inept secret agent, Johmy English.

Bom in the north-taut of England in 1958 Mikinson wat always shy at sxhool, ber be soon discovered than be could make his elassenntes langh by pulling grosesque faces, which zot him like nackname 'Moonman'. At this stage in his life, he had few thonglus of a career is ewerainenent.

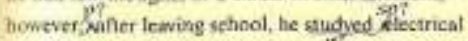
ingiatering at Nenasile Universityfond thes wett on to Oxfioed to do a mariers degrece. There, he hegan to take comedy mone seriously, appeating in a mumber of eomedy productions and at the Edinhusgi Feuival.

Hes appearances on TV in the popular comedy series Not the Nine O'Clock Newx' helped him to get his firnt filma role is 1963 in the James Band film Never Say Never Again'? Fiet le was unknown outside the UK ustil he developed the tharaster of Mr Beise who, he says, is based on himselr at the uge at ien. The TV programmes thase been shousc in eighty couptos ox hand in 1997 she frature film 'Bean; The Movie' becane the second biesest-earning Wisritish film ever.

Despite his worltuide fame, Atkinson avoifts publicity. rarsly appearing in pablic and almost never buxing? interviews He lives quietly shith lais wife Sunetra and their two child deen, and listit is known of Ais privase life - apan from his lowe of classic racing cars. As be says about himself, $T$ am essentially a rahler quiet, dull persae who jus happens to be a perfoemer 2 C ?

\section{Wordspot get}

1 Match the meanings of get with the examples in the diagram below

\begin{tabular}{|lll|}
\hline arrive & become & catch \\
obteinireceive & phrasal verbs & understend
\end{tabular}

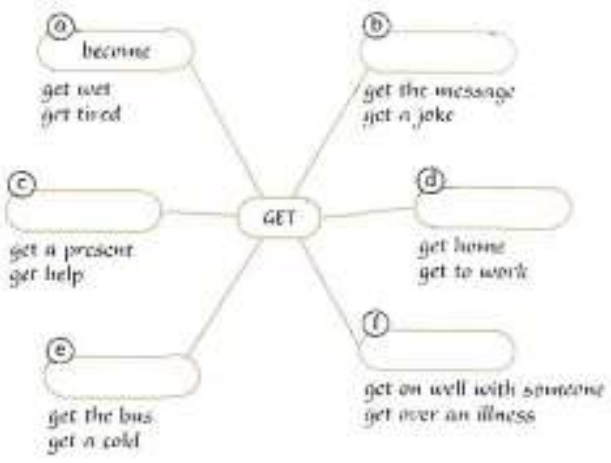

2 Add these phrases to the diagram above.

\begin{tabular}{|lll|}
\hline get a better job & get betteriworse & get angry \\
get an early light & get $E 0,060$ a year & get loct \\
get on with your work & get there & get a sheck \\
Idon't get whot you maan & get into trouble & get stuck \\
\hline
\end{tabular}

3 Work in pairs. Student A: Look at page 138

Studem B: Look at page 141.

4 Can you find someone in the class who ...

a got home late lost night?

- got stuek in bod trofnc an their way to work/school?

gets a lot of colds?

d doesn't get an very well with their next door neighbours?

e got a really spocial present for his/her last birthday?

f gat lost toe nrst time they came to this school?

9 is gerting the bus home todoy?

h ofen gels tired in the iniddle of the aftemoon?

1 rarely gess angry?

1 gat into trouble a lot at primory school?

Decide what questions you will ask betore you begin, and speak to as many students in the class as you can. 
Yabancı Dil Eğitiminde Yazma Eğitimi Yaklaşımlarının Gözden Geçirilmesi ve Yazma

Becerisinin Diğer Becerilerle İlişkilendirilmesi

module 3 Adventures and mishaps

\section{Writing A narrative}

1 Look at the photo and read the story of what happened wtren the Erown tarnily visited the Grand Camyon. Which way of speing the Grand Caryan does Mrs Brown think is best?

2 Read the description of how the narrative is structured, and complete the gaps with the words and phrases from the box.

the setting
the clienax
on unexpected problem an amiasing condusion
the main charocten the begirning
an intetesting nes chasocter

- Patagraph A introduces stecinodie divinateis and providei __ for the story.

- Ponagraph B describes the firs: part of the stary and how fels.

- Parograph C binngs in

- Porograph D continues the story introduong

- Ravegrapls E doscribes stery, and uses of the events more vivid.

- Poragrapb F provides to make th links back bo which

3 a You are going to write a story about a 3 frightening experience You can choose scmetring that happened to you or to someone you know, or an kncident fram a book ar film that you like

b $5 p e n d$ about ten minutes plinning how to tell the story. Use the ideas in exercise 2 to help you.

4 Write a first draft of your story. Resd it through to check that you have used the correct rarrative tenses. Show vour first draft to your teacher or another student. Does heishe have any suggestions?

5 Write the final draft of your story. Oisplay the staries around the class so that you can read each other's. Which story did you like best?

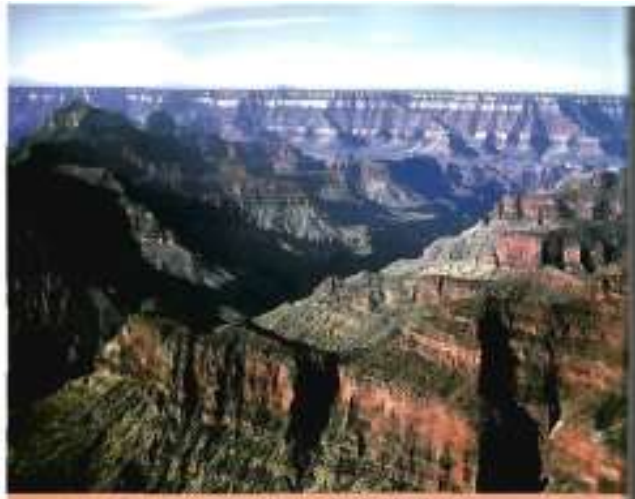

The Girand Canyon is a popular bourist destination in porth-west Averons, USA known for its omrazing rock formations.

A They say there 8 er three wavs to excerence the Cand Canyon on foct, on mues $\alpha$ try ar. Wo chose the frst. Up early, my hushand Dave and I and cur three kids - teernagers Matt and Lian end Itila Laura, egeis six - cound 't wat to gat sterted. We dooded to wilk abanga bively peeth ramed Enicht Arcasl Tral My hisband had spoken so a cark ranger who told him thet welking to the first wator station would be co problem.

a As the ffve of us set out, I was shocked at haw zarrow the path was - thane seemed to de no micre than thirty centimetrea between us and faing hundreas of metres to our deaths. And । couldn't bels noticing that the cehter hiluers warch ' dnssed ike 48. They had hatwy tackpecks and woter botties, strong leather boots and hass. in cur shores. F-sirts and treinars wo fat very under-dressed.

c We weked and woked ... but unforturately the besuly of the Carych was ipet on us. As the sun rees hipher. Artzona's tamouis heet seened to raast La. There was ne shode ond oit less were activg. Wh chocidad to go back, with Lava on my back and the boys for batind. By the trme we finaly got back, Qur iegs were like jaly.

D The root chey atter wa'd had a kono rest and a good croakiagt. we were ready tor another viow of tha Camon i., by al, After our walk the prenious dsy, this would be the tasiest thingt in tha werld. For \$200, we rented a amal plare. The plot, Joe, was handsomin and hony. He joked with the iedsa and put us al we our ease.

E Wio colles to each otmer exchedly as the plene tock ot and cincled anound the Caryon. Eut tha smies on our feoses varisted as Jso tcsesed the plene around, pretencing he was. gong to crash and shourthy. This is the exact spot whare

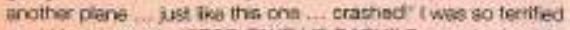
could baretr orok, 'STOP, TAKE US BACX't Butwe hed paid for fifteen minutes of airsme, ard bat s what we gat. When we

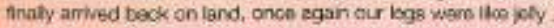
but this time, it weat from fear, not irechess 'No hardly spokn cs wo drava back

F As f wad, there ses trres wons to waw the Grand Comon; on fost on mibe or by ar. We nnwer tried the muss, but persentaly rd recommend a fourth: buy yeuroel a gosd mstazire $1 \mathrm{ke}$ Nabonal Googrephic. That wex you can boe the Canyon and you dom tend kp as endusted nervous wrock. 


\section{PROJECT - BRITISH PRESS SURVEY}

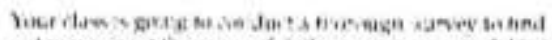

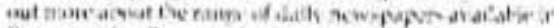

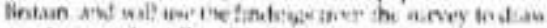

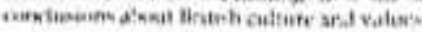

Yus will nowd

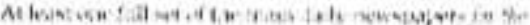

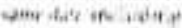

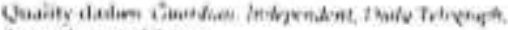
lamis tomentiol lives

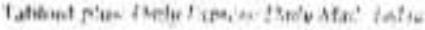

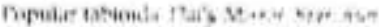

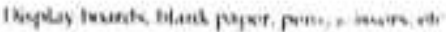

\section{SIACI ONI}

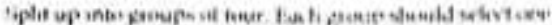

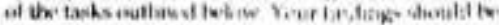

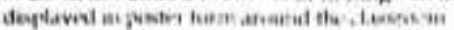

\section{Alleration of spare}

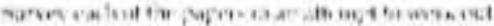

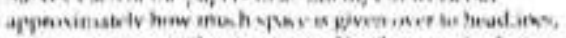

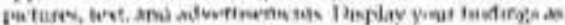

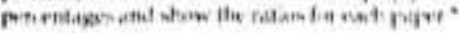

Cournt

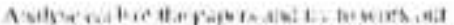

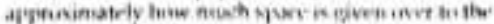
Radirwave:

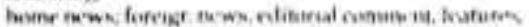

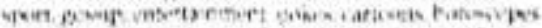

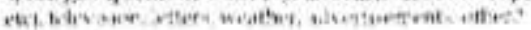

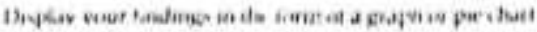

Fnat pare analysis

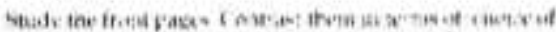

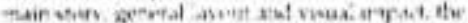

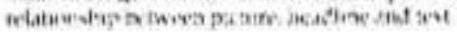

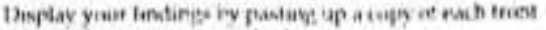

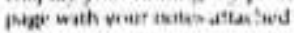

\section{Headline anabysis}

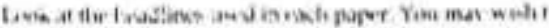
nemader the for'tow inis

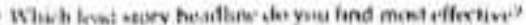

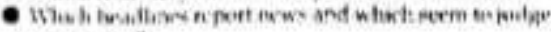

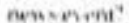

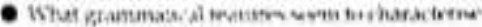

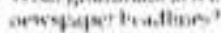

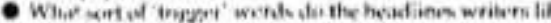
binse'

- What esampiles of with plav can vis tiad?

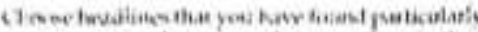

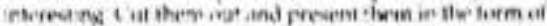
powtest drowaly

\section{Mylisin andyois 1}

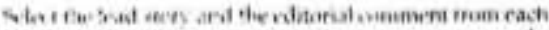

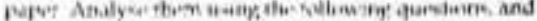

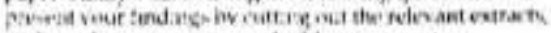

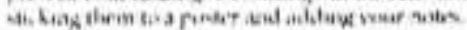

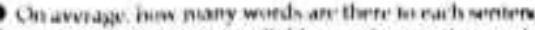

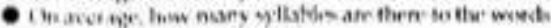

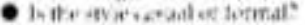

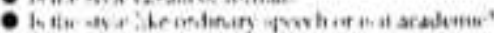

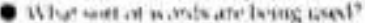

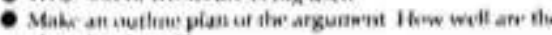

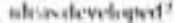

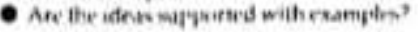

Analvois uf advertionarnts

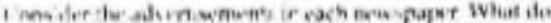

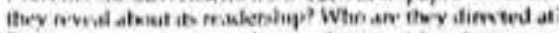

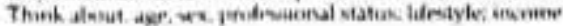

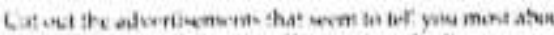

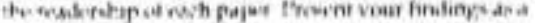
poler ilioplas

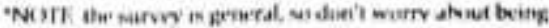
tur mathernaticalle prisioe

\section{STACL. IWW}

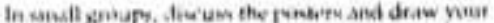

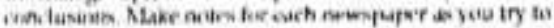

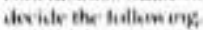

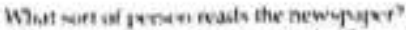

IV)

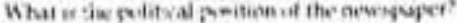


Yabancı Dil Eğitiminde Yazma Eğitimi Yaklaşımlarının Gözden Geçirilmesi ve Yazma Becerisinin Diğer Becerilerle İlişkilendirilmesi

\section{STACETHREE}

The class should divide inso threx groups. Croup $A$ should eoncern itend with the quality papers: group B with the tabloid plus' group of popers, Croun C with the popular abloids

Imagine that you have to prepare a lecture on Einhsh culturs for an audienre of new students The endy resource you hawe is your set of newspopers Selnct cxamples from the newspupers to use in your lecture and peepare your infure nates. The lecture should last for not more than sevm minutes. You may wish so cansider the following:
Bribsh politic: the Roysl Family, spont and leieure interests grader issues racial issues: Bntish gorsip, the lifestylies depicted by the advertisemenis

STAGE FOUR

Elest yout speaker and deliver your lecturt, camplete with its evampiles

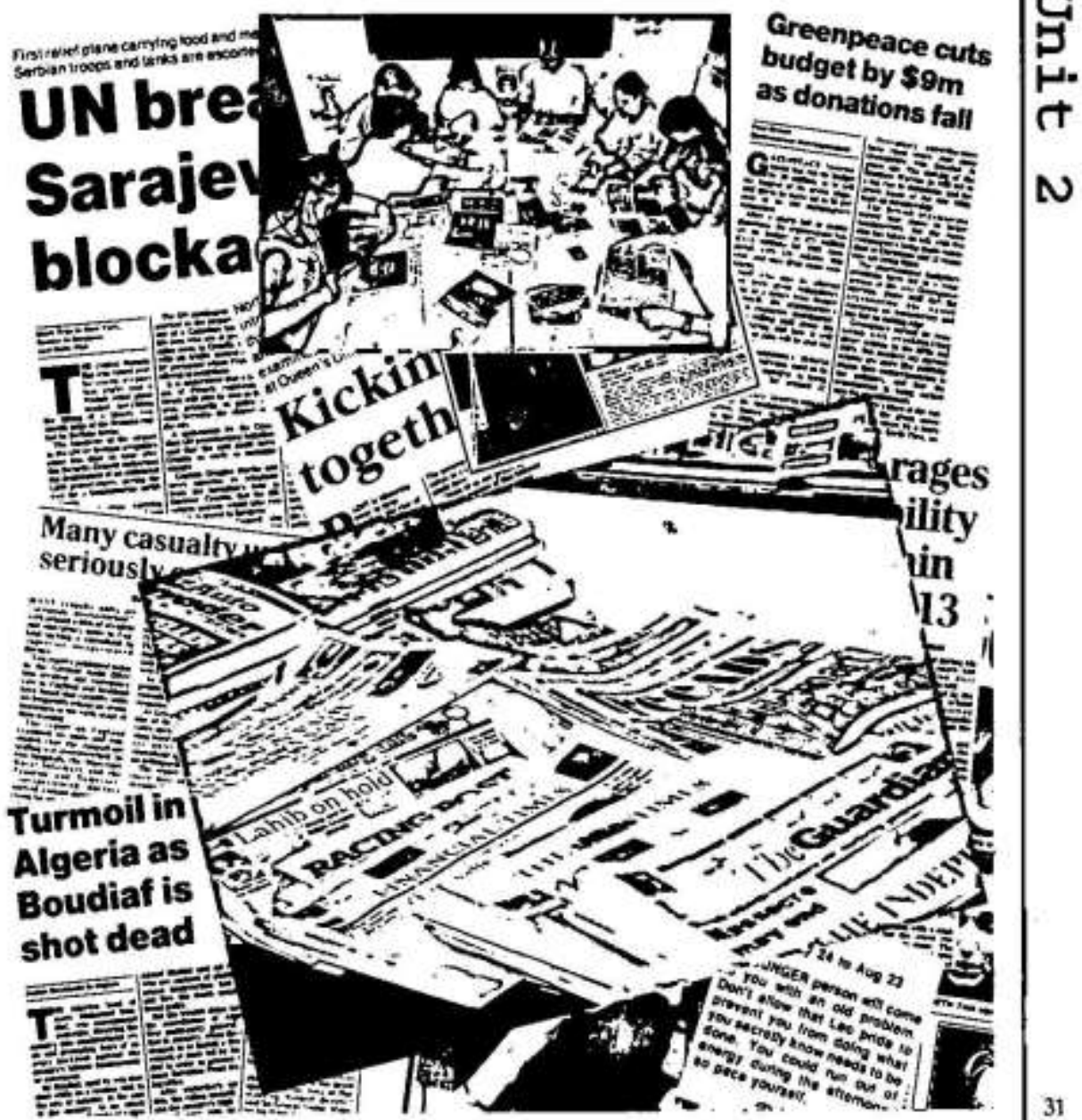




\section{REVIEW}

\section{PROJECT EVALUATION}

(1) stage one

How useful did you find this as a way of analyaing the British Press? How satisfied wete you with your poster display? Wruse down any posiner comments you havr about the other penters

\section{Q Siage two}

Write duwn the five most important discovenies that you made during this activity. Thry may be to do with the differences between the newspapers, panicular paints abost individual pupers. Hrihsh eociery in general, yautself or yout ktougn. When you have finished. circulate your comments ornund the class.

\section{Stages three and four}

What wete yout cantributians in tine discussion and th the wrising of the lerture plan? How well arganiond was the plan? Haw well did your group suppont the poims yau were making with rasmples? Inw vuccesstul was. the incture? What cnteris do yeu have for jud ging the sucress if such a presentation?

\section{THINKING ABOUT WRITING}

Diferens people have diffetent needs when wrihing in English. Each person has a diflereat appercarh, too Working in pairs, complesc the following usk.

GMake a list of alt the situatinats where you have to write in Finglish when you are in yper awn counery, then list all the situations where you have is weite in Enylish whele you are in Hritain.

6 Have you ever writien any of the fotluwng in Enylish?

letters, posicandx, busines lesters. Fiter forms, inmices, teicies, fisis, a currifulum vitae (roumt). menimaniels,

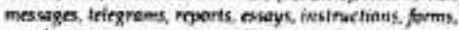
nouds, stones, perms, noles, diary, reconds, exrmises. summarits, address broks, graffit

GSilect two tiems fenm the hist above and say what char actertses the panicular type nf writing

Erample

Essay

Acodemic, farmal, otien fet an zudience of above-average inielligence and with a common imerest Well-arganised, often pernassive and informative. showing specialist knowled ge Found in newspapers and joumatism, peactised in scluseis, urivensties ve. A inren nt cxaminatinn asserssment

You nend not, of murse, express your ideas as formully as this - just say whasever serens to you to te felevant and true)

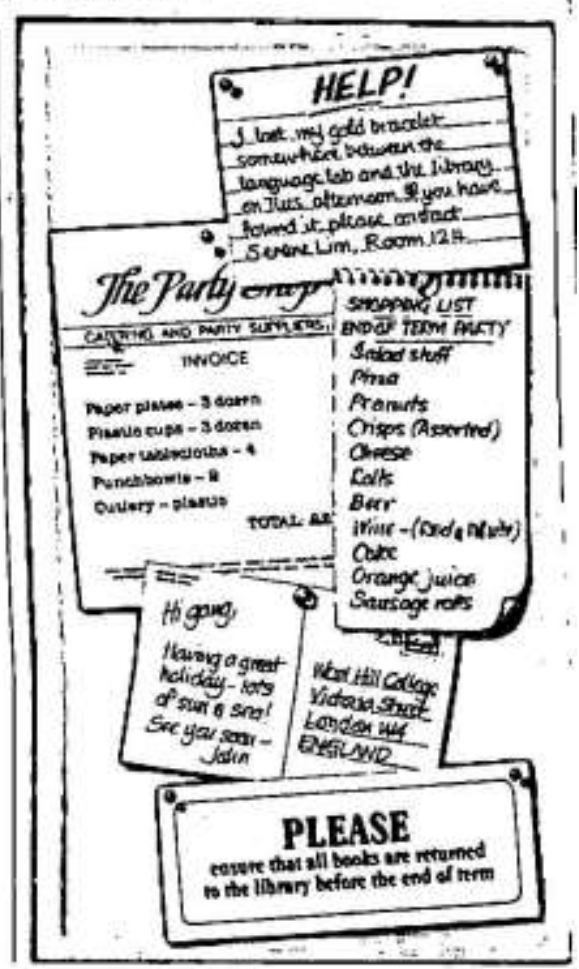


Yabancı Dil Eğitiminde Yazma Eğitimi Yaklaşımlarının Gözden Geçirilmesi ve Yazma

Becerisinin Diğer Becerilerle İlişkilendirilmesi

\section{HOW WELL DO YOU WRITE}

CIn pairs, consider the following sasiements. Dn ymu agrex or diagroe with them? (When you cannol simply agrec et disagrec. pou may rewrite the suatement ]

I think that my spetting is bad. Bad spetling showrs up a bad writer

When i witle in Engith i chwors worry coout my gammo: Inever know what is conect and whet the noyt terse is

Yes. gramor ond spelling ore important but above oll eise the viting mint be well organined and well loid out in order to make senne.

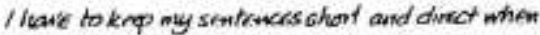
I write in the Englioh langrage:

thove a thorough strategy for checking everything ingi i witte in Engtsh

I am not ashamed of ong mintakes. I nsk native spookers co help ne ot elso 1 pess it to. fttond. I an always cataful about tianslating stiniahe ftos my nother tongue.

I have to spend a lot of time. planning my uriting.

\section{WRITINC}

8Choose one of the following writing tacks. When yen have firushed, show your wotk 10 others in the class. This can be a good slarting pnint for improving your writing and uvetcoming the feat of writiag in Englieh

a Ohoose one of the news photogyaphs and wate the newspapet siony.

h Oroose one of the newspaper photographs and then write s front page story around it that you might find in The Independent and in The San. Be carctul to contrast the style of your writing as well as the content

e. Write a full report on the newspaper survity you did in this und imugios that you anc writiag in for a student who was unatie to take part in the propct

A The main function of ncwspopors is to make money: Discuss this statement

f Write a general escay companing ond contrating the newspapers in your country with those in Bniain.
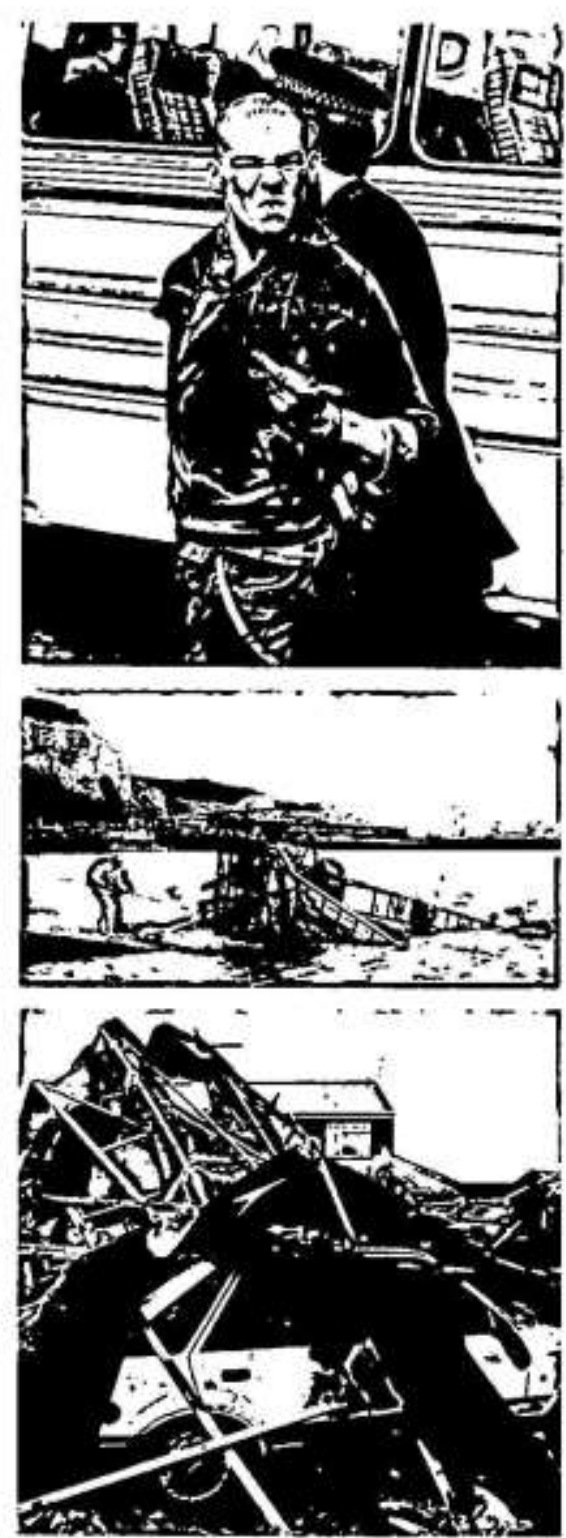


\section{Kaynakça Bilgisi / Citation Information}

Akbaş, E. (2020). Yabancı dil eğitiminde yazma eğitimi yaklaşımlarının gözden geçirilmesi ve yazma becerisinin diğer becerilerle ilişkilendirilmesi. OPUS-Uluslararası Toplum Araştırmaları Dergisi, 16(30), 3038-3082. DOI: 10.26466/opus.744508 